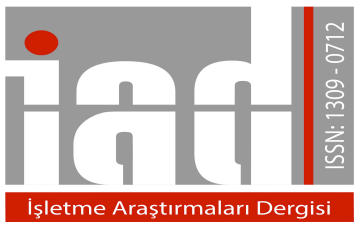

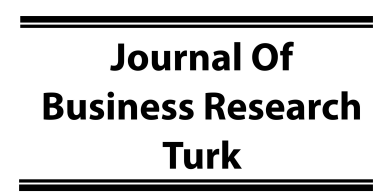

www.isarder.org

\title{
Finansal Sürdürülebilir Büyüme Oranı ve Finansal Oranlar: Borsa İstanbul İmalat Sanayi Üzerinde Bir Araştırma \\ Financial Sustainable Growth Rate and Financial Ratios: A Research on Borsa İstanbul Manufacturing Firms
}

\author{
Arzu ŞAHİ ${ }^{1}$ \\ Adana Bilim ve Teknoloji Üniversitesi \\ İşletme Fakültesi \\ Uluslararası Ticaret ve Finans Bölümü, \\ Adana, Türkiye \\ orcid.org/0000-0002-9944-1791 \\ asahin@,adanabtu.edu.tr
}

\author{
Bahadır ERGÜN \\ Adana Bilim ve Teknoloji Üniversitesi \\ İşletme Fakültesi \\ Uluslararası Ticaret ve Finans Bölümü \\ Adana, Türkiye \\ orcid.org/0000-0002-0844-412X \\ bergun@adanabtu.edu.tr
}

\section{Özet}

Bu çalışmada, finansal sürdürülebilir büyüme oranından (SGR) sapmanın finansal oranlar ile ilişkisinin incelenmesi amaçlanmıştır. Bu kapsamda, Borsa İstanbul'da listelenen 69 halka açık imalat sanayi firmasının 2013-2015 dönemi 3 yıllık ortalama verileri üzerinde, gerçekleşen büyüme oranı (AGR) ve Higgins (1977) SGR'si belirlenmiştir. AGR-SGR farkının, aktif karlılığı, öz kaynak karlılığı, fiyat/kazanç oranı, borçlanma oranı ve cari orana etkisinin araştırılması ve SGR'nin en etkili bileşeninin belirlenebilmesi amaciyla korelasyon analizi ve tek değişkenli yatay-kesit regresyon analizi yöntemlerinden faydalanılmıştır. İncelenen 69 firmanın 3 yıllık ortalama SGR'si $\% 10$ iken aşırı büyüyen 46 firmanın SGR'si \%6, yetersiz büyüyen 23 firmanın SGR'si \%18 dir. Analiz bulgularına göre AGR-SGR farkı ile aktif ve öz kaynak karlılı̆̆ arasında negatif ilişki bulunmaktadır. SGR'nin en etkili bileşeni kar marjıdır. Genel olarak, aşırı büyüyen firmaların düşük karlılıkları nedeniyle daha düşük SGR ile faaliyet gösterirken yetersiz büyüyen firmaların yüksek karlılıklarının yüksek SGR'ye yol açtığı sonucuna varılmaktadir.

Anahtar Kelimeler: Finansal Sürdürülebilir Büyüme Oranı, Sürdürülebilir Büyüme Oranından Sapma, Aktif Karlılığı

\section{Abstract}

In this study, it was aimed to examine the relationship between the deviation from financial sustainable growth rate (SGR) and the financial ratios. In this context, actual growth rate (AGR) and Higgins (1977) SGR were determined over the 3-year average of 2013-2015 period of 69 publicly traded manufacturing companies listed on the Borsa İstanbul. Correlation analysis and univariate cross-section regression analysis methods were utilized to investigate the effect of $A G R$-SGR difference on the return on assets, return on equity, pricelearnings ratio, debt ratio, current ratio and to determine the most influential component of SGR. The 3-year average SGR of 69 firms examined was

\footnotetext{
${ }^{1}$ Sorumlu yazar
} 
$10 \%$, while the SGR for the 46 over-growing companies was $6 \%$ and for 23 undergrowing companies SGR was $18 \%$. According to the findings of the analyses a negative relationship between the AGR-SGR and the return on asset and return on equity was found and it was seen that the most influential component of SGR was profit margin. Overall it was concluded that over-growing firms operated with lower SGR due to their low profitability while high profitability of under-growing firms led to high SGR.

Keywords: Financial Sustainable Growth Rate, Deviation from Sustainable Growth Rate, Return on Assets.

\section{Giriş}

Satış büyümesi bir işletme için performans göstergelerinden biri olsa da (Momčilović, Begović, Tomašević \& Ercegovac 2015: 63) her zaman maksimize edilmesi gereken bir durum değildir. Hızlı büyüme, yöneticiler, hissedarlar ve piyasa açısından olumlu karşılanmasına rağmen finansal kaynak ihtiyacının yönetilememesi durumunda iflas riskini beraberinde getirmektedir. Yavaş büyüyen firmalar ise hissedarların büyüme baskıları yanı sıra atıl fonların yönetimi gibi sorunlarla karşı karşıya kalmaktadır. Robert C. Higgins (1977) tarafından öne sürülen "sürdürülebilir büyüme oranı" (sustainable growth rate [SGR]) bazı varsayımlar altında firmaların finansal kaynaklarını tüketmeden satışlarında gerçekleştirebileceği maksimum artış oranını ifade etmektedir (Higgins, 2012: 123). Bir firmanın gerçekleşen büyüme oranı (actual growth rate [AGR]) ile sürdürülebilir büyüme oranını karşılaştırmak, yönetimi ilgilendiren temel finansal konularda önemli bilgiler ortaya çıkarmaktadır. Gerçek büyüme sürdürülebilir büyümeyi aştı̆ğ zaman yönetim, bu genişlemeyi finanse edecek fona odaklanacaktır, tersi durumda gerçek büyüme sürdürülebilir büyümenin gerisinde kaldığında ise nakit fazlasını üretken bir şekilde kullanmaya yönelecektir (Higgins, 2012: 141). AGR'nin SGR'den yüksek olması sorunu aşırı büyüme (veya hızlı büyüme) sorunu, tersi durum ise yetersiz büyüme (veya yavaş büyüme) sorunu olarak ifade edilebilir. SGR, sektörlerin veya firmaların potansiyel büyüme sorunlarını belirlemek ve finansal performansı büyüme yönetimine odaklanan bütüncül bir yaklaşımla değerlendirmek için bir araç olarak kullanılabilir. Firmanın finansman ve işletme stratejisini ortaya koyan SGR bileşenlerinin incelenmesi, büyüme yönetimi yetersizliğinin neden olduğu sorunların kaynaklarına işaret edebilir.

Literatür incelemesinde, SGR'den firma ve sektör düzeyinde, büyümeyi yönetme ve performans ölçüm aracı olarak faydalanıldığı gözlenmiştir. Bu çalışmalar SGR modeli geliştiren, SGR gelişimine göre sektörlerin ve firmaların büyüme durumunu değerlendiren, SGR'nin veya SGR'den sapmaların firma performansına etkisini analiz eden uluslararası çalışmalardır. Packard (1957), kendi firmasına uyguladığ sürdürülebilir büyüme formülü ile Gordon (1962) ve Babcock (1970) geliştirdiği kar payı büyüme modelleri ile işletmeler için sürdürülebilir satış büyümesi modeline temel oluşturmuştur. Higgins (1977) daha önceki yazarların görüşlerini birleştirerek (Seens, 2013: 3) literatürde yaygın olarak kullanılan SGR modelini oluşturmuştur. Daha sonra yapılan çalışmalar genellikle Higgins (1977) modelini değiştiren/geliştiren ve/veya varsayımlarını genişleten modeller üretmiş, farklı modelleri karşılaştırmış ve büyüme modellerini ülke, sektör ve firma düzeyinde uygulamıştır. SGR modellemeye odaklanan çalışmalardan Firer (1995) mevcut borç oranı yerine hedef borç oranını dikkate alan, Platt, Platt ve Chen (1995), finansal sıkıntıda olan firmalar için kullanılabilecek, Hamman (1996), Burger ve Hamman (1999), Churchill ve Mullins (2001) nakit akımını dikkate alan SGR modelleri geliştirmiştir. Ashta (2008), Higgins modelinde dönem baş1 
aktif değerinin kullanımını öneren, Huang ve Liu (2009) kaldıraç etkisine dayalı olan, Yakimova (2013) ise sermaye yoğun şirketler için uygun olan bir SGR modeli geliştirmiştir. Fonseka, Ramos, Tian (2012) SGR modelleri karşılaştırması yapmıştır. Chen, Gupta, Lee ve Lee (2013), yeni öz kaynak ihracına izin vererek Higgins modelini genişletmiş, Mubeen (2017) ise Chen vd. (2013) tarafından modellenen görüşü uygulamalı olarak teyit etmiştir. SGR büyüklüğü, gelişimi ve AGR'den farkına göre sektör ve firmaları değerlendiren çalışmalardan Phillips, Anderson ve Volker (2004), SGR'nin küçük perakende şirketlerde uygulanmasının faydalı olacağını savunmuş, Seens (2013) Kanada'da KOBİ'lerin SGR'den az büyüdüğünü ortaya çıkarmıştır. Clouse ve McFaddin (1994), ABD doğal gaz sektörünü, Sempath ve Kambil (2005) S\&P 500 firmaların1, Pandit ve Tejani (2011) Hindistan tekstil-giyim sektörünü, Momčilović vd. (2015) Belgrad Borsası tarım ve gıda sektörü firmalarını, Jagadish (2011) Hindistan teknoloji firmalarını, Chang (2012) ise havayolu endüstrisini incelemiştir. SGR düzeyinin veya SGR'den farklı büyümenin finansal oranlarla ilişkisini araştıran çalışmalardan Xiyuan ve Jingui (2015), Çin Borsasından, Rahim ve Saad (2014), beş Asya ülkesinde, Hartono ve Utami (2016) Endonezya için SGR ile finansal oranların ilişskisini analiz etmiştir. Amouzesh, Moeinfar ve Mousavi (2011) İran Tahran Borsasında AGR-SGR farkının finansal oranlarda yarattı̆̆ değişimi araştırmış, Saputro ve Purwanto (2013) ise Endonezya Borsasi'nda finansal oran ve hisse senedi getirisinin AGR-SGR farkı üzerindeki etkisini incelemiştir. Yanı sıra Olson ve Pagano (2005), ABD'de banka birleşmelerinin uzun dönemli performans ölçümünde SGR'den faydalanırken Lockwood ve Prombutr (2010), ABD pazarında SGR ve hisse getirileri arasındaki ilişkiyi araştırmıştır. Wet (2013) ise hisse başına kar büyümesinin hesaplanmasına ilişkin bir kısıtın sebebini SGR varsayımları ile açıklamıştır.

Mubeen (2017) çalışması dışında Türkiye'de yer alan sektör ve firmalar için SGR hesaplayan yeterli çalışmanın bulunmadığı gözlenmiş olup bu çalışmada, Türkiye'de faaliyet gösteren firmaların finansal açıdan sıkıntıya düşmeden ve faaliyet politikalarını değiştirmeden sürdürebileceği büyüme oranının belirlenmesi, aşırı ve yetersiz büyüme durumlarının ortaya çıkarılması ve SGR'den sapmanın bazı finansal oranlara etkisinin incelenmesi amaçlanmıştır. Bu kapsamda, Türkiye'de halka açık imalat sanayi firmaları arasından belirlenen 69 firmanın 2013-2015 yılları ortalamalarından oluşan veri seti için Higgins (1977) SGR'si belirlenmiş, SGR'nin AGR'den farkı alınarak, bu farkın aktif karlılığı, öz kaynak karlılı̆̆ı, fiyat kazanç oranı, cari oran ve borçlanma oranına etkisi incelenmiştir. Korelasyon analizi ve tek değişkenli yatay kesit regresyon analizi bulguları, AGR-SGR farkının aktif karlılığ1 ve öz kaynak karlılığı ile ilişkisinin negatif olduğunu, bu negatif ilişkinin aşırı ve yetersiz büyüyen firmaların kar potansiyeli farklılığını yansıttığını göstermektedir. $\mathrm{Bu}$ bulgulardan firma yöneticilerinin, yatırımcıların ve finansal kurumların faydalanacağı düşünülmektedir.

Çalışmanın giriş bölümünün ardından ikinci bölüm ile SGR kavramı ve formülüne yer verilmiştir. Üçüncü bölümde literatür araştırması özetlenmiş, dördüncü bölümde veri setinin oluşturulması ve analiz yöntemi detaylandırılmış, beşinci bölümde analiz bulgularının yorumları sunulmuştur. Altıncı bölümde ise sonuç ve öneriler aktarılmıştır.

\section{Finansal Sürdürülebilir Büyüme}

Varlık fiyatlamada Gordon'un (1962) büyüme modeli kullanılırken, işletme finansmanında Higgins (1977) finansal sürdürülebilir büyüme oranı modeli yaygın olarak kullanılmaktadır (Mubeen, 2017: 38). Gordon (1962) çeşitli varsayımlar altında 
kar payının büyüme oranını belirleyerek hisse senedi fiyat modeli oluşturmuştur. Higgins (1977) bir firmanın büyüme hedefi ile finansman politikasının uyumunu test etmek için sürdürülebilir büyümeyi hesaplayan bir model geliştirmiştir. Finansal sürdürülebilir büyüme kavramı Higgins (1977) ile birlikte anılmasına rağmen 1950'lerde uzun süreli büyümenin firma karları ile desteklendiği sürece mümkün olduğunu hissedarlara açıklayan Hewlett-Packard firmasına kadar dayanmaktadır (Seens, 2013: 2). Packard (1957)'a göre belirleyici faktörü finansal kaynaklar olan büyümenin formülü karlılık ile aktif devir hızının çarpımıdır. 1963 yılında kurulan Boston Consulting Grup (BCG, 2014)'un Zakon başta olmak üzere şirket liderleri de sürdürülebilir büyümeyi sağlamaya önem vermiştir. Babcock (1970), sürdürülebilir büyümenin tek kaynağının alıkonulan karlar olduğunu belirterek büyümeyi sürdürülebilir ve sürdürülebilir olmayan bileşenlerine ayırmıştır. Yazara göre, sürdürülebilir bileşeni kar marjı, devir hızı, kaldıraç ve vergilere dayanan firmanın kazanma gücü ile bağlantılıdır. Sürdürülemez bileşeni ise sürdürülebilir büyümeden sapmaları ifade etmektedir.

Higgins (1977), diğer yazarların bulgularını da birleştirerek (Seens, 2013: 3) büyüme ve finansman politikası ilişkisini inceleyebilmek için birtakım varsayımlarda bulunmuştur. Yazar, enflasyonun olmadığı, amortismanın mevcut varlıkların değerini korumaya yettiği ve pazar koşulları el verdiği sürece satışların artırılabildiği bir ortamda satışlarını belli oranda artırmak isteyen bir firma olduğunu varsaymıştır. Bu firmanın kar marjı, aktif devir hızı, hedef sermaye yapısı, hedef kar dağıtım politikasını koruduğu ve ortaklarının yeni öz kaynak ihracına istekli olmadığ 1 da modelin dayandığ temel varsayımlardır (Higgins, 1977: 8; Higgins, 2001: 117). Artan satışlar, her tür varlığa daha fazla yatırım yapmayı gerektirir. Alıkonulan karlar ve alıkonulan karlarla orantılı yeni borç ihracı, bir miktar fon yaratsa da bu fonlar sınırlı olacaktır. Yeni hisse senedi ihracı ya da sermaye yapısını değiştiren yüksek miktarlarda borçlanma olmadan bu limit, kaynakları zorlamadan elde edilebilecek büyüme için bir üst sınır oluşturur. $\mathrm{Bu}$ sınır, firmanın sürdürülebilir büyüme oranıdır. Satışların büyüme oranını sınırlayan oran, öz kaynak genişleme oranı olduğu için bir firmanın sürdürülebilir büyüme oranı aslında öz kaynak büyüme oranıdır. Yeni hisse senedi ihraç etmeme varsayımı altında Higgins SGR modelinde öz kaynağ1 artırabilecek tek kaynak alıkonulan karlar olacaktır (Higgins, 2012: 124-126). Bu durumda büyüme oranı 1. Eşitlikte olduğu gibi yazılabilir;

$$
\mathrm{SGR}=(\mathrm{R} \times \mathrm{Net} \text { Kar }) / \text { Öz } \mathrm{kaynak}_{\mathrm{db}} \quad \text { 1. eşitlik }
$$

SGR, sürdürülebilir büyüme oranını; R, firmada alıkoyulan kar oranını veya temettü oranının birden farkını ifade etmektedir. Net Kar/Öz kaynak oranı öz kaynak karlılı̆̆ını (ROE), db ise dönem başı değerini göstermektedir. Bu sebeple SGR, 2. eşitlikte olduğu gibi tekrar düzenlenebilir (Higgins, 2012: 126);

$$
\mathrm{SGR}=\mathrm{R} \times \mathrm{ROE}_{\mathrm{db}} \quad \text { 2. eşitlik }
$$

Performansı bileşenlerine ayırmak için kullanılan temel eşitliklerden birini sağlayan (Babcock, 1970: 110) DuPont analizi ile SGR de bileşenlerine ayrılmıştır (Costa, 1997). Dupont analizinde ROE, faaliyet verimliliği (kar marjı), aktif kullanım verimliliği (aktif devir hızı) ve finansal kaldıraç (öz kaynak çarpanı) şeklindeki üç bileşeninin çarpımına eşittir (Ross, Westerfield \& Jordan, 2003: 105-106). SGR' nin çarpanı olan ROE'yi belirleyen faktörler aynı zamanda SGR'nin de belirleyicileridir. SGR, ROE DuPont eşitliğinin alıkoyma oranı (R) eklenmiş şeklidir (Ross vd. 2003: 
145). 2. eşitliğin performans bileşenlerine ayrılması ile 3. eşitlik elde edilir (Higgins, 2012: 126);

$$
\begin{aligned}
& \text { SGR = PRAT } \\
& \mathrm{P}=\text { kar marjı (net kar/satışlar) } \\
& \mathrm{R}=\text { alıkoyma oranı (1-temettü oranı) } \\
& \mathrm{A}=\text { aktif devir hızı (satışlar/toplam aktif) } \\
& \mathrm{T}=\text { öz kaynak çarpanı (toplam aktif / öz kaynak } \mathrm{db}_{\mathrm{db}} \text { ) }
\end{aligned}
$$

Kar marjı (P) ve aktif devir hızı (A), firmanın faaliyet performansını özetlerken, alıkoyma oranı (R) ve öz kaynak çarpanı (T) firmanın temel finansman politikasını tanımlamaktadır. Alıkoyma oranı, yönetimin kar payı dağıtma tutumunu, aktif-öz kaynak oranı ise finansal kaldıraç konusundaki politikasını yansıtmaktadır. Sürdürülebilir büyüme oranı, sabit olduğu varsayılan bu dört oran ile uyum içerisinde olan satış büyüme oranıdır. Firma bu orandan farklı bir oranda satışlarını artırmak için bunlardan birini ya da bir kaçını değiştirmelidir (Higgins, 2012: 126). Alıkoyma oranı ve finansal kaldıracın çarpımı firmanın alıkonulan karlar ve borç ile faaliyetlerini finanse etmek için birleşik finansman faktörünü yansıtmaktadır (Lockwood ve Prombutr, 2010: 520). SGR, P ve A'nın çarpımı olan firmanın aktif karlılığı (veya aktif getirisi-ROA) ve birleşik finansman faktörü ayrılarak 4. eşitlikte olduğu gibi de ifade edilebilir (Higgins, 2012: 127).

$$
\mathrm{SGR}=\mathrm{RT} \times \mathrm{ROA}
$$

4. eşitlik

4. eşitlik finansman politikaları sabitken SGR'nin ROA ile doğrusal bir ilişkisinin olduğunu ifade etmektedir. SGR oranında büyüyen bir firmada satış artışı aktif getirisini artırarak dengeli büyüme gerçekleşir. SGR dışında gerçekleşen dengesiz satış büyümesi, dengesiz büyümeden kaynaklanan nakit fazlalarını veya nakit açıklarını yönetmeyi gerektiren "sürdürülebilir büyüme sorunu" (sustainable growth challenge) yaratmaktadır (Higgins, 2012: 127-128). SGR'den farklı hızda olan AGR, sabit finansman politikas1 ile uyumlu değildir ve firmalar bu koşullarda finansman hedeflerine ulaşamazlar. $\mathrm{Bu}$ durumda üst yönetim pasif kalıp bu durumu görmezden gelerek finansal hedeflerine ulaşmada sürekli başarısız olmayı göze alır veya aktif olarak birbiriyle uyumlu büyüme ve finansal hedefler geliştirir (Higgins, 1977: 11). Aşırı büyümeyi (AGR > SGR) yönetmede karşılaşılan finansal problemler yetersiz büyümeye nazaran daha zahmetlidir (Higgins, 1977: 11). Bu durumda üst yöneticinin üç seçeneği bulunmakta olup bunlar; yeni hisse senedi ihraç etmek, PRAT'den biri ya da bir kaçını değiştirerek denge sağlamak ve son olarak gerçek büyümeyi azaltmaktır (Higgins, 1977: 15). Faaliyet etkinliğini artırmak her zaman mümkün değildir ve finansman politikalarını değiştirmek akıllıca olmayabilir. Aşırı büyüme, öngörülmesi ve yönetilmesi gereken finansal sıkıntılar yaratır. Özellikle satışlarını sürekli artırmak isteyen küçük firmalar karlı olsalar dahi, artan nakit ihtiyaçlarını borç kapasitelerini dolduruncaya dek borçlanmalarını artırarak giderir ve sonunda temerrüde düşebilirler (Higgins, 2012: 127). Büyümeyi dengeye getirmek için yapılacak diğer değişikliklerin her birinin kendi içinde barındırdığı riskler bulunmaktadır. Yetersiz büyüyen (AGR $<$ SGR) firmalar (Higgins, 2012: 136) ise ihtiyaç fazlası naktin nasıl değerlendirileceği konusunda sorun yaşar ve bu nakiti, likit varlıklarda artış, borçlarda azalış veya kar dağıtımında artış şeklinde kullanabilir. Firma, yeterli büyüme sorununa kalıcı bir çözüm üretemiyorsa bu durumda yönetimin uygulayabileceği üç seçenek; pasif kalmak, fazla fonu hissedarlara dağıtmak veya hızlı büyüyen bir şirketi satın almak olarak sıralanabilir (Higgins, 1977: 
11; Higgins, 2012: 136-138). Yetersiz büyüme, şirketin finansal kaynaklarını hissedar değeri üretmek için kullanmaması olarak da yorumlanabilir (Sempat \& Kambil, 2005: 2).

\section{Literatür Araştırması}

Literatür araştırmasının sonuçları beş alt bölüme ayrılarak sunulmaktadır. SGR modeline temel oluşturan öncül çalışmalar birinci grubu, model üretmeye veya geliştirmeye odaklanan çalışmalar ikinci grubu oluştururken, SGR veya AGR-SGR farkına göre sektör ve firmaların performansını değerlendiren çalışmalar üçüncü grupta sınıflandırılmıştır. Dördüncü grup SGR veya AGR-SGR farkının finansal oranlar ve finansal performans ile olan ilişkisini analiz eden uygulamalı çalışmaları içermektedir. Beşinci grup ise ilk dört kategori dışında kalan ve SGR'nin farklı kullanım alanlarını içeren üç çalışmadan oluşmaktadır.

Birinci grupta firmaların finansal ve faaliyete ilişkin temel dengelerini değiştirmeden sürdürebilecekleri büyüme modelini tanımlayan ve modelleyen çalışmalar bulunmaktadır. Packard (1957), 1950-1957 yılları arasında ortalama \%42 büyüyen Hawlat Packard firmasının bu hızlı büyümeyi kar ile finanse edilebilen yıllık büyüme oranı \%45 olduğu için sürdürülebildiğini belirtmiştir. Firmanın ortalama \%10 kar marjı ve 4.5 aktif devir hızının çarpımı şeklindeki büyüme formülü, ortaklık şeklini, borç yapısını ve işin diğer temel özelliklerini değiştirmeden firmanın ne kadar hızlı büyüyebileceğini göstermektedir (Packard, 1957: 2-3). Gordon (1962), firmanın yeni hisse ihraç etmediği, sabit borç-öz kaynak oranı ile gelirinin belli bir oranını alıkoyduğu ve yatırımından belli bir getiri elde ettiği varsayımları altında hisse fiyatını kar payı büyümesi ile ilişkilendiren fiyat modeli oluşturmuştur (Gordon, 1962: 38). Kar marj1, sermaye devir hızı, finansal kaldıraç, vergi oranı ve öz kaynak defter değeri ve bu faktörlerdeki değişime bağlı olarak hisse başına kar büyümesinin eşitliğini yazan Babcock (1970), öz kaynak defter değerinde değişime yol açan alıkonulan karların büyümenin sürdürülebilir kaynağı olduğunu ve SGR'den sapmaların sürdürülebilir olmadığını savunmuştur. Yazar, 1954-1965 yıllarındaki 11 yıllık sürede 30 Dow Jones firması arasından en yüksek SGR'ye sahip olan firmaların dönem sonunda en yüksek hisse başına kazanç oranına sahip olduğunu göstermiştir (Babcock, 1970: 108-113). Öz kaynak karlılığı ve alıkonulan karların bir fonksiyonu olarak geliştirdiği SGR modelini ABD imalat sektörüne 1974 yılı için uygulayan Higgins (1977), \%10.5 SGR ve \%3.8 AGR ile sektörün büyüme oranlarının finansman politikaları ile uyumlu olmadığını göstermiştir. Costa (1997), teorik çalışmasında finans yöneticilerinin, 1990'lı y1llarda ABD'de gerçekleşen çok hızlı büyümeleri yönetmeleri için seçebilecekleri araçlardan birinin de sürdürülebilir büyüme yönetimi olduğunu ifade etmiştir.

İkinci grupta sınıflandırılan çalışmalar mevcut SGR modelini geliştiren ve modelleri kıyaslayan çalışmalardır. Firer (1995), Higgins modelinde kullanılan dönem başı öz kaynak kullanımının iyi öngörüler sunduğunu ve yeni hisse senedi ihracının karı sulandırma etkisi açısından SGR'yi nasıl etkilendiğini göstermiştir. Ayrıca Firer (1995) mevcut borçlanma düzeyinde belirlenen SGR'ye ilave olarak hedef borçlanma düzeyinde belirlenen ulaşılabilir büyüme oranını (affordable growth rate) hesaplayarak SGR ile kıyaslamıştır. Platt vd. (1995), yeni borç alma kapasitesi bulunmayan finansal sıkındaki firmalar için SGR formülü geliştirilmiştir. Yazarlar geliştirdikleri oranın, finansal pazara giremeyen/sınırlı giren firmalar için olduğu kadar borçlanma oranlarını düşürmek isteyen firmalar için de büyüme stratejilerini yönlendirme aracı olarak 
kullanılabileceğini savunmuştur. Muhasebe verilerine dayanan geleneksel SGR'yi firmanın nakit pozisyonunu yansıtmadığı yönünde eleştiren yazarlar nakit akımını dikkate alan SGR modelleri geliştirmiştir. Hamman (1996), ilave borç ve öz kaynak ihracı olmadan sadece faaliyet nakit akışından elde edilen nakit akımına odaklanan SGR üreterek bunu bir firma ile örneklendirmiştir. Burger ve Hamman (1999), hedef nakit dengesini koruyan nakit akım SGR'sini tanımlamış ve geleneksel SGR ile arasında farklılıkları tespit etmiştir. Benzer şekilde Churchill ve Mullins (2001), firmanın mevcut faaliyet nakit akımları ile sürdürebileceği "kendini finanse eden" bir büyüme modeli geliştirmiş ve kuramsal bir firma için hesaplama yapmıştır. Rădăşanu (2015), geleneksel ve nakit akım SGR modellerini karşılaştırdığ 1 teorik çalışmasında, Hamann (1996) ve Churchill ve Mullins (2001)'in görüşlerini destekleyerek nakit akım SGR'sinin daha iyi bir büyüme ölçümü olduğunu savunmuştur. Satışların dönem başı aktiflerle yaratıldığı ve dönem başı aktifinin dönem başı öz kaynak ile zaman uyumu içinde olduğu görüşünden hareketle Ashta (2008), Higgins SGR formülünde dönem baş1 aktif değerinin kullanılmasının uygun olduğunu savunmuş ve bu savını bir örnek ile açıklamıştır. Higgins ve Van Horne ${ }^{2}$ modellerini karşılaştıran çalışmalardan Huang ve Liu (2009), iki modelde farklı ifade edilen finansal kaldıraçların kara etkisini incelemiş ve kaldıraç etkisine dayalı bir SGR modeli oluşturmuştur. Fonseka vd. (2012), ise her iki modelin birçok yaygın finansal özellik açısından oldukça benzer sonuçlar verdiğini ancak Higgings modelinin karı yüksek firmalar için daha yüksek SGR hesaplarken, Van Horne modelinin borçlanması yüksek firmalar için daha yüksek SGR değeri aldığını göstermiştir. Yakimova (2013), sermaye yoğun şirketlerin gelecekteki mali performansını tahmin etmek için perspektif analizi ile düzeltilmiş bir SGR modeli geliştirmiş ve bu modelin bir örnek ile uygulamasını gerçekleştirmiştir. Yatırım ve finansman kararını birlikte değerlendiren Chen vd. (2013), Higgins (1977) SGR modelini yeni öz kaynak ihracına izin vererek genişletmiş böylece varlık artışının diş öz kaynak, iç öz kaynak (alıkonulan kar) ve borç ile finanse edilmesine olanak tanımıştır. Çalışmada yeni hisse ihracından doğacak büyüme kaynağının eksikliğinden dolayı Higgins modelinin SGR'yi düşük hesapladığını göstermiştir. Yazarlar, kârlılık ve büyüme oranı riski arasındaki kovaryansı dikkate alarak büyüme ve kar payı dağıtma oranını birlikte optimize eden dinamik bir model geliştirmiştir. Mubeen (2017) ise Chen vd. (2013) tarafından modellenen bu görüşü ampirik olarak yedi gelişmekte olan ülke pazarında teyit etmiştir. Her ülkeden farklı sayıda firma verisi ile toplam 1046 firmanın 2010-2015 yılları verileri kullanılarak, ikincil öz kaynak ihraç eden ve etmeyen firmaların büyümesi arasındaki fark ölçülmüştür. Mubeen (2017), Higgins SGR'sinin düşük değerleme yapmasının olası sebebinin ikincil hisse ihraç etmek olduğunu beş pazar için teyit etmiş ve Chen vd. (2013) modelinin yeni hisse ihraç eden işletmeler için tercih edilebileceğini göstermiştir. Çalışmada ayrıca, finansal olmayan firmalar için SGR'nin düşük değerlenmesinin firmaya özgü faktörlerinin, kaldıraç ve büyüklük olduğu ortaya çıkmıştır.

\footnotetext{
${ }^{2}$ Van Horne, Higgins teorisine dayalı olarak sürdürülebilir büyüme oranını "belirli bir faaliyet, borç ve kar payı dağıtım oranı altında bir firmanın satışlarında gerçekleştirilen maksimum yıllık büyüme oran olarak" tanımlanmıştır (Xiyuan \& Jingui, 2015: 33). Higgins SGR modelinde alıkonulan kar değişimi $(\triangle \mathrm{RE})$ ve başlangıç öz kaynak değerine (OE) odaklanılırken, Van Horne SGR modelinde satış tutarının değişimine $(\Delta \mathrm{S} / \mathrm{S})$ odaklanılmaktadır. Bu durumda Higgins SGR " $\Delta R E / O E$ ” ifadesinin, Van Horne SGR ise " $\Delta \mathrm{S} / \mathrm{S}$ " ifadesinin nicel açıklamasıdır (Huang \& Liu, 2009: 200). Van Horne SGR modeli, aktif devir hızını (aktif/satış) ve öz kaynak çarpanını (borç/öz kaynak) hesaplama şekli ile Higgins SGR modelinden farklılaşmaktadır (Horne \& Wachowicz, 2008: 190-191).
} 
Üçüncü gruba dahil edilen araştırmalar SGR düzeyini ve gelişimini, AGR ile SGR ilişkisini inceleyerek veya AGR ile SGR farkını yorumlayarak firma ve sektörlerin büyüme performansını ve büyüme potansiyelini araştırmıştır. KOBİ'lerin içsel fonlarla ve sürdürülebilir düzeyde büyümesi gerektiği görüşünden hareketle Phillips vd. (2004), 1998-2000 yılları arasında ABD perakende sektörünü farklı büyüme döngüsü aşamalarına ayırarak Higgins (1977) SGR modeli çerçevesinde incelemiştir. Bulgular SGR'nin özelikle küçük özel sermayeli perakende şirketler için doğru büyüme oranı olduğunu göstermiştir. Kanada'da KOBİ'lerin destekleyebilecekleri SGR ve SGR'nin gerçek büyümeden ne kadar farklılaştığı sorularına cevap arayan Seens (2013), 20002010 döneminde 850.000 Kanada KOBI'sinin özet finansal tablosunu analiz etmiştir. Çalışma sonuçları, 11 yıllık ortalama SGR'si \%7.3 iken AGR'si \%3 olan KOBI'lerin büyüme potansiyelini gerçekleştiremediklerini göstermiştir. SGR'lerin temel belirleyicisi net kar marjındaki değişimlerin yanı sıra alıkoyma oranı ve finansal kaldıraçtır. Ayrıca sektörler arasında farklılık gösteren SGR'nin en yüksek olduğu sektör inşaat sektörü ve nispeten hizmet sektörüdür. Clouse ve McFaddin (1994), ABD doğal gaz sektörünün 1970-1990 yılları arasındaki SGR ve AGR'lerini inceleyerek sektörün geçmiş büyüme performansını incelemiş ve büyüme potansiyeli hakkında çıkarımlarda bulunmuştur. Sempath ve Kambil (2005), S\&P 500'ün 2004 yılı SGR'sinin beklenen 3 yıllık büyüme oranından yüksek olduğunu hesaplamıştır. 11 sektöre göre sonuçları raporlayan araştırma sonucu, S\&P 500 şirketlerinin likidite fazlasına sahip olduğunu ve ortalama olarak yeni hisse ihraç etmeden büyümeye devam edebileceklerini göstermektedir. Pandit ve Tejani (2011), yüksek büyüme potansiyeli olan perakende sektörünün büyümesinin sürdürülebilirliğini incelemek için Hindistan tekstil-giyim perakende sektöründe faaliyet gösteren 8 firmanın 2006-2010 yılları arasındaki SGR'lerini incelemiştir. Sektör verimliliğinin ve performansın göstergesi olarak kullanılan SGR, gerçekleşen büyümenin altında kalmıştır. Yazarlar bu farklılığın aktif performansını ve kaldıracı daha iyi yöneterek giderilebileceğini önermiştir. Momčilović vd. (2015), Sırbistan Belgrad Borsasında işlem gören 30 tarım ve 30 gıda sektörü firmasının 2011 ve 2012 yılları SGR'lerini sektör beklentileri açısından değerlendirilmiştir. SGR'lerin sektörler ve yıllar arasında önemli düzeyde farklılaşmadığı ve sadece 2011 yılı gıda sektörünün enflasyonun üzerinde reel SGR'ye sahip olduğu bulunmuştur. Rekabet avantajına sahip olduğu için seçilen her iki sektörün iki yıl içinde sınırlı büyüme potansiyeli olduğu sonucuna varılmıştır. Jagadish (2011), SGR'nin bileşenlerinin SGR üzerindeki etkisini, SGR ile AGR arasındaki ilişkiyi Hindistan'ın iki teknoloji firmasının 1999-2007 yılları verileri üzerinde test etmiştir. Hızla büyüyen Hindistan teknoloji pazarından bu iki firmanın içsel olarak üretilen fonlarla başarılı büyüdüğünü göstermiştir. Havayolu endüstrisinin uzun vadeli gelişimini ve finansman yeteneğini değerlendirmeye yardımcı olmak için Higgins SGR'sini inceleyen Chang (2012), KLM ve Air France şirketinin birleşme nedeninin büyüme sorununa çözüm getirmek olduğu görüşünü öne sürmüştür.

SGR oranının ve/veya SGR ile uyumlu veya uyumsuz büyümenin firmanın finansal oranlarıyla olan etkileşimini analiz eden makaleler ise dördüncü grup olarak sınıflandırılmıştır. Xiyuan ve Jingui (2015), Çin'in yüksek teknoloji içerikli ve büyüme potansiyeli yüksek olan yüksek girişimler pazarında (GEM) listelenen 28 şirketin 20102013 yılları finansal SGR'lerinin mevcut durumunu ve SGR'yi etkileyebilecek başlica faktörleri incelemiştir. Wilcoxon işaret sıralama testi ve faktör analizi sonuçları, ilgili şirketlerin aşırı büyüyerek SGR'yi başaramadığı ve SGR'de etkili olan beş faktörün; karlılık, nakit yaratma yeteneği, borç ödeme kabiliyeti, işletme kapasitesi ve büyüme 
kabiliyeti olduğunu göstermiştir. Rahim ve Saad (2014), Malezya, Endonezya, Tayland, Singapur ve Filipinler olmak üzere beş Asya ülkesinin Bursa Malezya Menkul Kıymetler Borsasında listelenen 229 şirketinin 2001-2012 dönemine ait 12 yıllık verisinden oluşan bir veri seti kullanarak SGR, sermaye yapısı ve firma performans1 arasındaki ilişkiyi incelemiştir. Sürdürülebilir büyümenin, sermaye yapısı oranlarına (borç-öz kaynak, toplam öz kaynak, toplam borç) ve performans oranlarına (aktif karlılığ1, hisse başına kar ve sermaye karlılı̆̆ 1 ) etkisi doğrusal regresyon ve ANOVA yöntemi ile analiz edilmiştir. Çalışma bulguları, tüm ülkelerde SGR'nin ROA ile ilişkili olduğunu (biri dışında pozitif ilişkili), diğer karlılık ve sermaye yapısı değişkenleri ile ilişsisinin sayısı, önemi ve yönünün ülkeler arasında farklılık gösterdiğini raporlamaktadır. Ayrıca analiz sonuçlarına göre ülkeler arasında sürdürülebilir büyüme açısından farklılık gözlenmezken şirketlerin sermaye yapısı ve performansı farklılık göstermektedir. Hartono ve Utami (2016), Endonezya Borsasında SGR'nin cari oran, aktif getirisi ve fiyat-kazanç oranı üzerindeki etkisini biri sürdürülebilirlik yatırım endeksi (SRI-Kehati) diğeri ise karşılaştırma ölçütü endeksi (IDX30) olmak üzere iki endeksin beşer firması üzerinde 2010-2013 verileri ile incelemiştir. Regresyon ve ttestleri uygulanarak, SGR'nin her iki endeks firmalarının aktif getirisi ile pozitif ilişkili ancak $\mathrm{F} / \mathrm{K}$ oranı ile negatif ilişkili olduğu ve sadece ilk endekste cari oranı pozitif etkilediği sonucuna varılmıştır. Amouzesh vd. (2011) tarafindan İran Tahran Borsasında listelenen 54 firmanın 2006-2009 yıllarını içeren üç yıllık verisi ile SGR-AGR farkı hesaplanmıştır. SGR'den sapmanın firma performansına (ROA ve piyasa-defter değeri) ve likiditesine (cari oran ve asit-test oranına) etkisi korelasyon ve regresyon analizleri ile test edilmiştir. SGR-AGR farkının aktif getirisi ve piyasa-defter değeri ile pozitif ilişkili olduğu, cari ve asit oran ile önemli bir ilişkisinin olmadığı sonucuna varılmıştır. Saputro ve Purwanto (2013), Endonezya Borsası'nda (IDX) listelenen 49 şirketin 20092011 yılları verilerine çoklu regresyon analizini uygulayarak AGR-SGR farkına, performansın (ROA ve piyasa-defter değeri oranı), likiditenin (cari oran ve asit oranı) ve hisse senedi getirilerinin etkisini ampirik olarak incelemiştir. Sonuçlar AGR-SGR sapması üzerinde, asit-test oranının pozitif, ROA ve cari oranın ise negatif etkisinin olduğunu göstermektedir. Piyasa-defter değeri ve hisse senedi getirilerinin sapma üzerinde etkisinin olmaması, büyüme oranlarının piyasa fiyatından çok şirket performansıyla ilgili olması şeklinde açıklanmıştır.

Son olarak SGR'nin farklı kullanım alanlarını içeren üç çalışma, literatür araştırmasının beşinci grubunu oluşturmaktadır. ABD'de banka birleşmelerinin uzun dönemli performans ölçümünde SGR'yi kullanan Olson ve Pagano (2005), satın alınan bankaların 1987-2000 yılları arasındaki üç yıllık anormal getirilerinin en önemli belirleyicisinin satın alan bankanın ele geçirme öncesi SGR'si, satın alım sonrası SGR'si ve kar payı ödeme oranındaki değişim olduğunu ortaya koymuştur. Lockwood ve Prombutr (2010), 1964-2007 yılları arasında ABD pazarında sürdürülebilir büyüme ve hisse getirileri arasındaki ilişkiyi inceleyerek yüksek SGR'yi düşük temerrüt riski, düşük defter değeri-piyasa değeri ve düşük gelecek getiriler ile ilişkilendirmiştir. Performans ölçümü olarak hisse başına karın kullanımını ve kısıtlarını 3 örnek olay ile inceleyen Wet (2013), HBK büyümesinin yüksek hesaplanmasına yönelik bir eğilimin bulunması kısıtının sebebini SGR formülündeki varsayımlardan yola çıkarak açıklamaktadır. 


\section{Veri ve Yöntem}

Bu çalışmada, Borsa İstanbul (BIST) imalat sanayii sektöründe listelenen 69 şirketin 2013-2015 yılları 3 yıllık ortalama verilerine göre finansal sürdürülebilir büyüme oranı ve gerçekleşen büyüme oranları arasındaki farkın aktif karlılığı, öz kaynak karlılığı, fiyat kazanç oranı, cari oran ve borçlanma oranına etkisi korelasyon analizi ve tek değişkenli yatay kesit regresyon analizi ile araştırılmıştır. Sürdürülebilir büyümenin bileșenleri olan kar marjı, alıkoyma oranı, aktif devir hızı ve öz kaynak çarpanının sürdürülebilir büyüme oranındaki etkinliği tek değişkenli regresyon analizi ile incelenmiştir. Ayrıca aşırı büyüyen ve yetersiz büyüyen firmaların büyüme ortalamalarının karşılaştırılması ve alt sektör ortalamalarının belirlenmesi yoluyla da değerlendirmeler yapılmıştır.

Higgins (1977) SGR modeline imalat sanayi üzerinde yaptığı uygulama ile ulaşmıştır. 2015 yılı itibari ile Türkiye'de imalat sanayinin 18 sektör içindeki payı satış büyüklüğüne göre yaklaşık \%50'dir (Türkiye Cumhuriyeti Merkez Bankası [TCMB], 2016: 6) ${ }^{3}$. Bu sebeple veri seti, araștırma tarihi (2017 Haziran-Aralık) itibari ile BIST imalat sanayi sektöründe sınıflandırılan halka açık 181 firma arasından belirlenmiştir. 181 şirketin heterojenliğini BIST pazar sınıflandırmasını dikkate alarak azaltmak için yakın izleme pazarında işlem gören 13 şirket, gelişen işletmeler pazarında işlem gören 9 şirket ve piyasa öncesi işlem platformunda yer alan 9 şirket veri setinin dişında tutulmuştur. Büyüklük açısından sadece A grubu şirketlerini veri setinde birakacak şekilde 40 adet $B$ grubu ve 12 adet $C$ grubu şirket de veri setinden çıkarılmıştır. 2013 ve sonrasında BIST'de işlem görmeye başladığı için analiz dönemine ait verisi bulunmayan 5 şirketin ve 3 yıllık analiz dönemi boyunca herhangi bir y1l dönem zararı bulunan 24 şirketin $^{4}$ de analiz dışında tutulması ile veri seti büyüklüğü 69 şirket olarak sınırlandırılmıştır. BIST'e kote olan 69 A grubu imalat şirketinin 3 yıllık (2013-20142015) finansal verisine dayanan değişkenler, Kamu Aydınlatma Platformunda (KAP) (www.kap.org.tr) yayınlanan finansal tablo ve dipnotlar aracılığı ile belirlenmiştir.

$\mathrm{Bu}$ çalışmada, firmaların finansman ve faaliyet politikaları ile uyumlu satış büyümesini modelleyen büyüme modellerinden yaygın olarak kullanılan Higgins (1977) SGR modeli kullanılmıştır. SGR, diğer çalışmaların bazılarında (Pandit \& Tejani, 2011; Hartono \& Utami, 2016; Amouzesh vd. 2011, Momčilović vd. 2015; Jagadish, 2011) olduğu gibi ve çalışmanın 2. bölümünde yer alan 2. eşitlikte belirtilen şekilde öz kaynak karlılığının alıkoyma oranı ile çarpımı şeklinde ( $\mathrm{SGR}=\mathrm{R} \times \mathrm{ROE}_{\mathrm{db}}$ ) hesaplanmıştır. Bununla birlikte SGR bileşenlerini inceleyebilmek amacıyla 3. eşitlikte (SGR = PRAT) olduğu gibi PRAT değişkenleri de belirlenmiş ve 2. eşitlik ve 3. eşitlik ile hesaplanan SGR'lerin eşit olduğu teyit edilmiştir. SGR, ilave öz kaynak ihraç etmeden gerçekleşebilen büyüme oranını ifade etmekte olup yıl içindeki öz kaynak artışlarını bu

\footnotetext{
${ }^{3}$ TCMB 2013-2015 Sektör Bilançoları Değerlendirme Raporunda 2015 yılı itibari ile imalat sanayinin 18 sektör içindeki payı satış büyüklügüune göre $\% 49.8$, aktif büyüklüğüne göre $\% 39.8$, çalışan sayısına göre \%50.7 ve firma sayısına göre \%37.1' dir (3.469 imalat sanayi firması) (TCMB, 2016: 6).

${ }^{4}$ Dönem zararı ve geçmiş yıllar zararları nedeniyle oluşan negatif öz kaynak değerleri değişkenlerde sapmalara neden olmaktadır. Dönem zararı, negatif SGR hesaplanmasına ve pozitif AGR durumunda AGR-SGR farkının çok fazla yükselmesine yol açacaktır. Dönem zararına ilave olarak geçmiş yıllar zararları nedeni ile eriyen veya negatife dönen öz kaynak ile faaliyet gösteren bir firmada öz kaynak karlılığı, SGR oranı ve dolayısı ile AGR-SGR farkı gerçeği yansıtmayacaktır. Amouzesh vd. (2011) çalışmasında da zarar eden firmalar analize dahil edilmemiştir.
} 
oranının dışında tutmak amacı ile Higgins (1977) tarafından önerildiği ve diğer uygulamalı çalışmalarda (Pandit \& Tejani, 2011; Lockwood \& Prombutr, 2010) görüldügü gibi hesaplamalarda dönem başı öz kaynak defter değeri (bir önceki yılsonu öz kaynak defter değeri) dikkate alınmıştır. AGR, cari yılsonu hasılat tutarının bir önceki yılsonu hasılat tutarına göre artış oranını ifade etmektedir. Hesaplamalarda kullanılan kar rakamı, firmanın ilgili döneminin net dönem karıdır ${ }^{5}$. Kar marjı (P), dönem net karının hasılata oranıdır. Alıkoyma oranı (R), bir önceki yıl net karının kar payı olarak dağıtılmayan kısmının dönem net karına oranlanması ile hesaplanmıştır ${ }^{6}$. Aktif devir hızı (A), hasılatın ilgili dönem aktif toplamına bölümüdür. Öz kaynak çarpanı (T), cari yıl toplam aktifin, dönem başı toplam öz kaynak tutarına oranını ifade etmektedir.

Finansal oranlardan ROA, 3 şekilde hesaplanmıştır. Amouzesh vd. (2011)'de olduğu gibi net karın, dönem başı ve dönem sonu aktif ortalamasına bölünmesi ile ROA(1) hesaplanmıştır. ROA(1) cari yıl karının, dönem başı ve sonu varlıklarının basit ortalamasının bir sonucu olduğunu ifade etmektedir. Ashta (2008), Lockwood ve Prombutr (2010) ve Jagadish (2011)'de olduğu gibi net karın dönem başı aktifine oranı ROA(2)'yi oluşturmaktadır. ROA(2), bir önceki yılsonu itibari ile elde bulunan toplam aktiflerin dönem karını ürettiğinin göstergesidir. Net karın, dönem sonu aktifine bölünmesi ile ilde edilen ROA(3) dönem boyunca yatırım yapılan aktiflerin dönem sonu bakiyesini o dönemin karı ile ilişkilendirmektedir. ROA(3) aynı zamanda SGR bileşenlerinden P ve A'nın çarpımına eşittir. AGR-SGR farkının ROE üzerindeki etkisi ise dönem başı öz kaynak değerini dikkate alan $\operatorname{ROE}(1)$ ile ve dönem sonu öz kaynak değerini kullanan $\operatorname{ROE}(2)$ ile incelenmiştir. $\operatorname{ROE}(1)$, SGR bileşenlerinden $\mathrm{P}$, A ve T'nin çarpımıdır. Analizin bağımlı değişkenlerinden Fiyat/Kazanç $(\mathrm{F} / \mathrm{K})$ oranı, BIST pay piyasası bülteni kapanış fiyatlarının pay başına düşen kazanç/kayıp (hisse başına kazanç/kayıp) ile oranlanması şeklinde elde edilmiştir. Firmaların finansal tablo dipnotlarında açıklandığı gibi pay başına kar, net karın ilgili dönem boyunca dolaşımda olan hisse senetlerinin ağırlıklı ortalama adedine bölünmesi ile elde edilen rakamı ifade etmektedir. $\mathrm{F} / \mathrm{K}(1)$, yılsonu $\mathrm{F} / \mathrm{K}$ oranlarının ortalaması iken $\mathrm{F} / \mathrm{K}(2)$, sadece 2015 yılsonu $\mathrm{F} / \mathrm{K}$ oranını yansıtmaktadır. $\mathrm{F} / \mathrm{K}(2), 3$ yılın büyüme oranlarının etkisinin 2015 yıl sonu $\mathrm{F} / \mathrm{K}$ oranına yansıyabileceği varsayımı ile analize dahil edilmiştir. Cari oran (cari), cari yıl dönen varlıklarının, cari yıl kısa vadeli yükümlülüklere oranı, borçlanma oranı (borç) ise cari yıl toplam kısa ve uzun vadeli borç tutarının cari aktiflere oranıdır ${ }^{7}$. Analizde kullanılan değişkelerin tanımlayıcı istatistikleri Tablo 1 ile verilmiştir. Aşırı büyüyen ve yetersiz büyüyen firmalar için ayrı tanımlayıcı istatistikler Tablo 2 ile sunulmuştur. Ayrıca değişkenlerin alt sektörlere ait ortalama değerleri Tablo 3 'de yer almaktadır.

\footnotetext{
${ }^{5}$ Kontrol gücü olmayan payları bulunan şirketlerde (AKCNS, ANACM, ASUZU, ARCLK, BOLUC, BRSAN...v.b.) ana şirket hissedarlarına ait net dönem karı dikkate alınmıştır.

610 firmanın (BRSAN, BFREN, EREGL, GUBRF, KONYA, KORDS, OTKAR, TOASO, TTRAK, ULKER) 13 gözleminde bir önceki yılın karını aşan kar dağıtımları yapılmıştır. Dipnotlar incelendiğinde temettü ödemesinin, bir önceki yıl karı ve geçmiş yıllar karından yapıldığı belirtilmiştir. Bu gözlemler için kar dağıtım oranı \%100 ve alıkoyma oranı " 0 " olarak dikkate alınmıştır.

${ }^{7}$ Borç oranı, finansal kaldıracın bir başka ifadesi olup aynı dönem verileri ile yapılan hesaplamalarda $\mathrm{T}=1 /(1$-borç) eşitliği sağlanmaktadır. Ancak SGR eşitliğinde bir önceki yılsonu (dönem başı) öz kaynak kullanımı, T ile borç oranının farklılaşmasına yol açmaktadır.
} 
Tablo 1. Tanımlayıcı İstatistikler, 69 Gözlemden Oluşan Tüm Veri Seti

\begin{tabular}{|l|c|c|c|c|c|}
\hline Değişken & Sembol & Ortalama & St.Sap & Min. & Max \\
\hline AGR-SGR fark1 & AGR-SGR & 0.02 & 0.12 & -0.27 & 0.58 \\
\hline Gerçekleşen Büyüme Oran1 & AGR & 0.12 & 0.10 & -0.09 & 0.61 \\
\hline Sürdürülebilir Büyüme Oranı & SGR & 0.10 & 0.10 & 0.01 & 0.51 \\
\hline Kar Marj1 & P & 0.11 & 0.07 & 0.01 & 0.29 \\
\hline Alıkoyma Oran1 & R & 0.54 & 0.32 & 0.06 & 1.00 \\
\hline Varlık Devir Hız1 & A & 0.99 & 0.43 & 0.31 & 2.79 \\
\hline Öz kaynak Çarpan1 & T & 2.33 & 1.17 & 1.15 & 7.61 \\
\hline Varlık Getirisi 1 (ortalama) & ROA (1) & 0.10 & 0.06 & 0.01 & 0.36 \\
\hline Varlık Getirisi 2 (dönem baş1) & ROA (2) & 0.10 & 0.07 & 0.01 & 0.43 \\
\hline Varlık Getirisi 3 (dönem sonu) & ROA (3) & 0.09 & 0.05 & 0.01 & 0.31 \\
\hline Öz kaynak getirisi (dönem sonu) & ROE (1) & 0.18 & 0.10 & 0.03 & 0.53 \\
\hline Öz kaynak getirisi (dönem baş1) & ROE (2) & 0.16 & 0.08 & 0.02 & 0.42 \\
\hline Fiyat/Kazanç oran1 & F/K (1) & 1,110 & 4,647 & 1.26 & 37,078 \\
\hline Fiyat/Kazanç oranı 2015 & F/K (2) & 1,527 & 7,353 & 0.92 & 58,500 \\
\hline Cari Oran & Cari & 2.29 & 1.23 & 0.91 & 6.17 \\
\hline Borçlanma oran1 & Borç & 0.42 & 0.19 & 0.11 & 0.84 \\
\hline Not. Analze dinl
\end{tabular}

Not. Analize dahil edilen 69 şirket (N=69) kodu; ADANA, ADEL, AFYON, AKCNS, AKSA, ALCAR, ALKIM, ANACM, ASUZU ARCLK, ARSAN, ASLAN, AYGAZ, BAGFS, BTCIM, BSOKE, BOLUC, BRSAN, BFREN, BRISA, BUCIM, CCOLA, CEMTS, CMBTN, CIMSA, DEVA, DYOBY, EGEEN, EGSER, ERBOS, EREGL, FROTO, GENTS, GOODY, GOLTS, GUBRF, HEKTS, JANTS, KARTN, KLMSN, KNFRT, KONYA, KORDS, KRSTL, KUTPO, MRDIN, TIRE, NUHCM, OTKAR, PARSN, PETKM, PETUN, PNSUT, SARKY, SASA, SODA, TATGD, TOASO, TRKCM, TMSN, TUPRS, PRKAB, TTRAK, TBORG, ULKER, UNYEC, VESBE, YATAS, YUNSA şeklindedir.

Tablo 1'den görüldüğü gibi A grubunda işlem gören 69 imalat sanayi firmas1 2013-2015 y1lları ortalama değerlerine göre \%10 SGR'ye sahipken $\% 12$ büyüyerek $\% 2$ aşırı büyüme sergilemiştir. Bu ortalamalar 2010-2015 yılları arasında Türkiye'de 55 firmanın ortalama Higgins SGR'sinin \%3,4, AGR'sinin \%16,7 olduğunu gösteren Mubeen (2017) çalışması ile uyumludur. Analiz şirketlerinin ortalama kar marjının $\% 11$, aktif getirilerinin \%9-10 ve öz kaynak getirilerinin \%16-18 olduğu ve karlarının \%54'ünü alıkoyduğu ${ }^{8}$ izlenmiştir. Aktif devir hızı yaklaşık 1 olan firmaların öz kaynak çarpanı 2.33'dür. F/K oranının ortalaması ve firmalar arasında gösterdiği değişkenlik yüksektir. 0.91 ile 6.17 aralığında olan cari oranın ortalama değeri 2.29 dur. \%84'e kadar çıkan borçlanma oranı ortalaması ise \%42'dir. Tablo 1 'in minimum-maksimum gözlemleri incelendiğinde, ortalama \%30 ROE, \%67 R, \%23 SGR ve -\%4 AGR ile AGR-SGR farkı en düşük (-\%27) olan şirket Tüpraş-Türkiye Petrol Rafinerileri A.Ş.(TUPRS)'dir. AGR-SGR farkı maksimum değeri (\%58) Kristal Kola ve Meşrubat Sanayi Ticaret A.Ş.(KRSTL)'ne aittir. KRSTL, ortalama \%3 ROE ve \%100 alıkoyma oranı ile \%3 SGR oranına sahipken ortalama satış büyümesi \%61 (aynı zamanda en yüksek AGR oranı) olarak gerçekleşmiştir. SGR'si en yüksek olan Türk Tuborg Bira ve Malt Sanayii A.Ş. (TUBORG), \%51 SGR, \%32 AGR ile -\%19 yetersiz büyüme

\footnotetext{
${ }^{8}$ Birçok firma gelirinin \%20 ila \%60’’nı alıkoymaktadır (Gordon, 1962: 47).
} 
sergilemiştir. TUBORG, genel ortalamaya ve yetersiz büyüyen firmalara göre yüksek olan karlılığ $(\% 20)$, alıkoyma oranı (\%100) ve kaldıracı (2.81) sayesinde \%45 ROE ile faaliyet göstermektedir. Konfrut Gıda Sanayi ve Ticaret A.Ş. (KNFRT), ortalamanın altında öz kaynak çarpanına (1.61) rağmen \%17 SGR potansiyeline sahipken -\%9 ile en düşük AGR'si olan firmadır.

3 yıllık ortalamalara göre 69 şirketin 46'sında aşırı büyüme (AGR-SGR >0), 23 'ünde yetersiz büyüme (AGR-SGR $<0$ ) durumu bulunmaktadır. Tablo 2, aşırı büyüyen (AB) 46 firmanın ve yetersiz büyüyen (YB) 23 firmanın tanımlayıcı istatistiklerini içermektedir. Tablo 2, veri setinin AGR-SGR farkının yönüne göre aşırı ve yetersiz büyüme durumunu ifade edecek şekilde ayrılarak, değişkenlerin iki grup arasında nasıl farklılaştığının incelenmesine olanak tanımaktadır.

Tablo 2. Tanımlayıcı İstatistikler, 49 Așırı Büyüyen, 23 Yetersiz Büyüyen Firma

\begin{tabular}{|l|c|c|c|c|c|c|c|c|}
\hline & \multicolumn{2}{|c|}{ Ortalama } & \multicolumn{2}{|c|}{ Standart Sapma } & \multicolumn{2}{c|}{ Minimum } & \multicolumn{2}{c|}{ Maksimum } \\
\hline Sembol & AB & YB & AB & YB & AB & YB & AB & YB \\
\hline AGR-SGR & 0.08 & -0.10 & 0.09 & 0.09 & 0.00 & -0.27 & 0.58 & -0.01 \\
\hline AGR & 0.14 & 0.08 & 0.09 & 0.10 & 0.05 & -0.09 & 0.61 & 0.32 \\
\hline SGR & 0.06 & 0.18 & 0.05 & 0.12 & 0.01 & 0.01 & 0.25 & 0.51 \\
\hline P & 0.09 & 0.13 & 0.07 & 0.07 & 0.01 & 0.04 & 0.28 & 0.29 \\
\hline R & 0.47 & 0.69 & 0.31 & 0.29 & 0.06 & 0.07 & 1.00 & 1.00 \\
\hline A & 1.00 & 0.97 & 0.46 & 0.38 & 0.31 & 0.46 & 2.79 & 1.73 \\
\hline T & 2.30 & 2.40 & 1.24 & 1.06 & 1.22 & 1.15 & 7.61 & 5.76 \\
\hline ROA (1) & 0.09 & 0.12 & 0.06 & 0.05 & 0.01 & 0.03 & 0.36 & 0.21 \\
\hline ROA (2) & 0.09 & 0.13 & 0.07 & 0.06 & 0.01 & 0.03 & 0.43 & 0.26 \\
\hline ROA (3) & 0.08 & 0.11 & 0.06 & 0.04 & 0.01 & 0.03 & 0.31 & 0.18 \\
\hline ROE (1) & 0.15 & 0.22 & 0.10 & 0.10 & 0.03 & 0.07 & 0.53 & 0.45 \\
\hline ROE (2) & 0.14 & 0.18 & 0.09 & 0.06 & 0.02 & 0.06 & 0.42 & 0.34 \\
\hline F/K (1) & 1,440 & 451 & 5,608 & 1,322 & 1.26 & 5.13 & 37,078 & 5,919 \\
\hline F/K (2) & 2,220 & 140 & 8,951 & 431 & 0.92 & 5.80 & 58,500 & 2,024 \\
\hline Cari & 2.23 & 2.42 & 1.21 & 1.30 & 1.02 & 0.91 & 6.17 & 6.04 \\
\hline Borç & 0.43 & 0.41 & 0.20 & 0.17 & 0.11 & 0.12 & 0.84 & 0.78 \\
\hline
\end{tabular}

Not. AB, aşırı büyüyen firmaları, YB, ise yetersiz büyüyen firmaları ifade etmektedir.

Tablo 2 ortalamaları ile aşırı büyüyen firmaların, aktif devrinin 0.03 daha hızlı olması dışında diğer SGR bileşenlerinin yetersiz büyüyen firmalara göre düşük olması nedeniyle daha düşük ROA, ROE ve SGR (\%6) ancak daha yüksek AGR (\%14) ile faaliyet gösterdiği gözlenmektedir. Ayrıca ortalamalar yüksek ROE ve R ile \%18 SGR potansiyeli olan YB firmaların \%8 AGR sergileyerek büyüme potansiyelini yakalamadığını göstermektedir. Yetersiz büyüyen firmalarda daha düşük olan $F / K$ oranının, büyüme kapasitesine ulaşamama durumunu yansıttığı düşünülebilir ${ }^{9}$. Aşırı ve yetersiz büyüyen firmalarının değişken ortalamalarını içeren Grafik 1 ile de yetersiz

\footnotetext{
${ }^{9} \mathrm{~F} / \mathrm{K}$ oranları şirketler arasında büyük farklılıklar göstermekle birlikte, yüksek F/K'lar genellikle firmaya ilişkin yüksek büyümeye beklentilerinin olduğu anlamına gelmektedir (Ross vd. 2003: 104).
} 
büyüyen firma grubunun SGR oranı, SGR'nın A dışında P,R,T bileşenleri, ROA, ROE ve cari oranının aşırı büyüyen firma grubuna kıyasla daha yüksek olduğu görülmektedir.

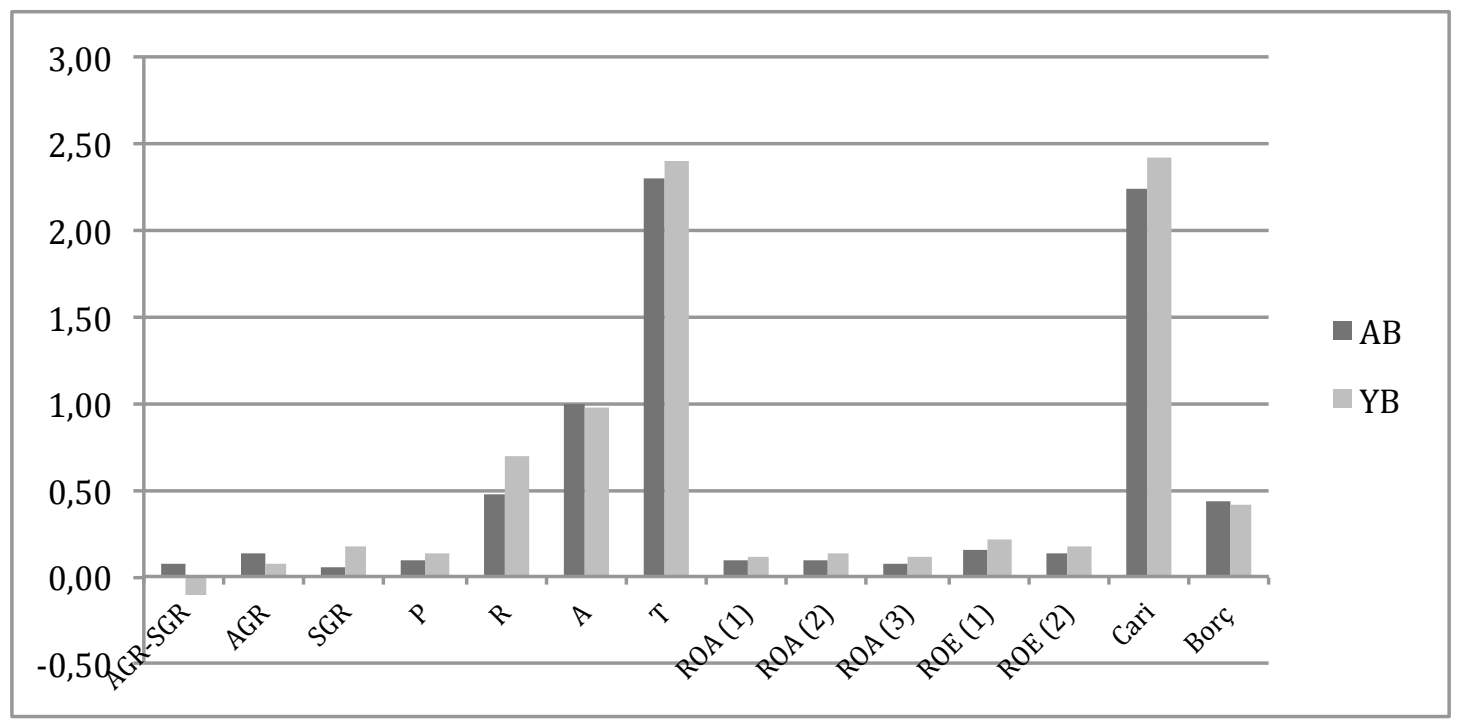

Grafik 1. Aşırı Büyüme ve Yetersiz Büyüme Durumlarında Değişkenlerin Ortalamaları

Not: Tablo 2'de yer alan aşıı büyüyen (AB) ve yetersiz büyüyen (YB) firmaların ortalama verileri ile oluşturulan grafiğe $\mathrm{F} / \mathrm{K}$ oranı dahil edilmemiştir.

İmalat sanayinin 9 alt sektörüne ait tanımlayıcı istatistikler Tablo 3'de verilmiştir.

Tablo 3. İmalat Sanayii Alt Sektörleri Değişkenleri

\begin{tabular}{|l|c|c|c|c|c|c|c|c|c|}
\hline Alt Sektör & AGR-SGR & AGR & SGR & P & R & A & T & ROA (2) & ROE(1) \\
\hline Taş ve toprağa dayalı (19) & 0.054 & 0.12 & 0.070 & 0.15 & 0.46 & 0.75 & 1.74 & 0.11 & 0.15 \\
\hline Metal ana sanayi (5) & 0.047 & 0.09 & 0.045 & 0.05 & 0.42 & 1.28 & 2.22 & 0.06 & 0.10 \\
\hline Orman ürünleri, mobilya (1) & 0.039 & 0.09 & 0.054 & 0.07 & 0.56 & 0.96 & 1.31 & 0.08 & 0.09 \\
\hline Gıda, içki, tütün (8) & 0.029 & 0.18 & 0.153 & 0.09 & 0.68 & 0.98 & 2.13 & 0.05 & 0.18 \\
\hline Metal eşya, makine, gereç yapım (15) & 0.027 & 0.15 & 0.123 & 0.09 & 0.51 & 1.15 & 2.92 & 0.09 & 0.25 \\
\hline Kağıt, kağıt ürünleri, basım, yayın (2) & 0.015 & 0.08 & 0.065 & 0.06 & 0.96 & 1.00 & 1.83 & 0.12 & 0.07 \\
\hline Dokuma, giyim eşyası, deri (4) & $-0.000^{*}$ & 0.09 & 0.086 & 0.09 & 0.64 & 0.83 & 2.71 & 0.06 & 0.13 \\
\hline Kimya, petrol kauçuk, plastik ürünler (14) & -0.033 & 0.08 & 0.108 & 0.09 & 0.57 & 1.10 & 2.72 & 0.12 & 0.18 \\
\hline Diğer imalat sanayi (1) & -0.036 & 0.16 & 0.200 & 0.23 & 0.53 & 0.78 & 2.17 & 0.26 & 0.38 \\
\hline
\end{tabular}

Not. Tablo 3, bazı değişkenlerin alt sektör ortalamalarını içermektedir. ROA ve ROE değişkenlerinin dönem başı aktif ve öz kaynak değerini dikkate alan versiyonlarına yer verilmiştir. Alt sektör adlarının yanında parantez içinde verilen firma sayıları, 69 firmanın alt sektörlere dağılımını göstermektedir. *Dokuma, giyim eşyası ve deri sektörünün AGR-SGR farkı -0,0001'dir.

2013-2015 dönemi ortalama verilerinin alt sektörler için ortalamalarını içeren Tablo 3, imalat sanayinin 9 alt sektörünün 6'sının SGR'nin üzerinde, 3'ünün SGR'nin altında büyüdüğünü göstermektedir. Taş ve toprağa dayalı alt sektörün SGR'si \%7 iken $\% 12$ büyüyerek en yüksek aşırı büyümeyi gerçekleştirmiştir. Genel imalat sanayi ortalamalarına göre (Tablo 1 ile verilen) AGR'si ortalama ile uyumlu ve kar marji ortalamanın üzerinde olan taş ve toprağa dayalı alt sektörün nispeten ortalamanın altında kalan alıkoyma, aktif devir hızı ve öz kaynak çarpanı nedeniyle düşük SGR 
üreterek aşırı büyüme sergilediği izlenmiştir. 19 firmayı içeren taş ve toprağa dayalı alt sektöründe AGR-SGR farkı en yüksek olan firmalar \%24 ile Aslan Çimento A.Ş. (ASLAN), \%22 ile Trakya Cam Sanayii A.Ş. (TRKCM), \%15 ile Batısöke Söke Çimento Sanayii T.A.Ş.(BSOKE) ve \%11 ile Adana Çimento Sanayii T.A.Ş. (ADANA) dir. Bu firmaların SGR'leri \%2 ila \%6 aralığında ancak AGR'leri \%14 ile \% 28 aralığındadır. Örneğin ASLAN firması ana ve alt sektör ortalamaları ile kıyaslandığında ortalamadan yüksek kar marjına (\%22) karşılık, düşük alıkoyma oranı (\%12), aktif devir hızı (0.58) ve öz kaynak çarpanı (1.5) ile \%2.2 oranında SGR'ne sahip iken \%26.6 büyümüştür. Aşırı büyüyen sektörlerden ikinci sırada olan metal ana sanayi alt sektöründe AGR-SGR farkı en yüksek olan firmalar 13\% ile Borusan Mannesmann Boru Sanayi ve Ticaret A.Ş. (BRSAN) ve \%7 ile Ereğli Demir ve Çelik Fabrikaları T.A.Ş. (EREGL)'dir. Gerçekleşen büyümesi 13\% olan ve finansal kaldıraçtan (3.4) faydalanan BRSAN'ın çok düşük olan SGR'sine düşük karlılık oranları (\%2 P ve \%3 ROE) ve alıkoyma oranı $(\% 17)$ ve nispeten düşük aktif devir hızı (0.61) neden olmuştur.

Yetersiz büyüme düzeyi en yüksek olan diğer imalat sanayi sektörü sadece ADEL firmasından oluşmakta olup şirket $\% 38 \mathrm{ROE}$ ve $\% 53 \mathrm{R}$ değeri ile ortalamanın üzerinden SGR potansiyeline sahip iken yeterli büyümemiştir. 14 firmadan oluşan kimya, petrol kauçuk ve plastik ürünler alt sektörü tüm imalat sanayi ortalamasının bir miktar üzerinde borç kullanımı, aktif devir hızı, alıkoyma oranı ve ortalamanın altında karlılığ ile \%11 sürdürülebilir büyüme potansiyeline sahip olmasına karş11ık \%8 büyüyerek potansiyelinin altında kalmıştır. Kimya, petrol kauçuk ve plastik ürünler sektöründe AGR-SGR fark1 -\%27ile en düşük olan TUPRS, \%4 olan kar marjını 1.73 aktif devir hızı ile \%7 ROA'ya ve 4.23 öz kaynak çarpanı ile \%30'a ROE'ye dönüştürmüştür. TUPRS, ortalamanın üzerinde SGR potansiyeli olan buna karşılık satışlarında \%5 düşüş yaşayarak yetersiz büyüyen sektör/firma kategorisinde yer alan bir firmadır. Bagfaş Bandırma Gübre Fabrikaları A.Ş. (BAGFS) \%28 SGR'ye sahipken bu orandan \%17.7 oranında daha az büyüyerek \%10 AGR gerçekleştirmiştir. Benzer şekilde Sasa Polyester Sanayi A.Ş. (SASA), Petkim Petrokimya Holding A.Ş. (PETKM), Soda Sanayii A.Ş. (SODA), Goodyear Lastikleri T.A.Ş. (GOODY) SGR'nin altında büyüyerek kimya, petrol kauçuk ve plastik ürünler alt sektör ortalamasını etkilemiştir.

\section{Bulgular}

AGR-SGR'nin belirlenen finansal oranlarla ilişkisi 69 gözlem sayılı 9 farklı eşitliğe uygulanan korelasyon analizi ve yatay-kesit analizi ile incelenmiş ve bulgular Tablo 4'de gösterilmiştir. Veri ve yöntem bölümünde açıklandığı şekilde elde edilen değişkenler arasındaki ilişkiyi analiz eden tahmincilerin istatistiklerini içeren Tablo 4'ün 3. sütunu her bir satırda belirtilen değişkenler ile AGR-SGR arasındaki korelasyon katsayısını ve önem seviyesini göstermektedir. 4. ila 8. sütunlar, tek bağımsız değişkenli yatay-kesit regresyonlarda bağımlı değişken ROA, ROE, F/K, Cari ve Borç oran/oranları iken parametre değerlerini ve test istatistiklerini içermektedir. Son 2 sütun ile gösterilen 2 ön test, değişen varyansın varlığına ait sonuçları içermektedir. 9. sütunda yer alan $\mathrm{BP} / \mathrm{CW}$ testinin sabit varyans hipotezi $\mathrm{F} / \mathrm{K}$ bağımlı değişkenli 6 . ve 7 . regresyonlar dışında kabul edilmekte iken aynı $\mathrm{H}_{\mathrm{o}}$ hipotezli White testi tüm regresyonlarda değișen varyans sorunu bulunmadığını ifade etmektedir. Ancak 2 eşitlikte değişen varyans sorunu bulunması ve yatay kesit verilerde değişen varyans sorununun yaygın olması nedeniyle dirençli standart hatalar hesaplanmıştır. 
Tablo 4. Varsayım ve Tahminci Test İstatistikleri (Finansal Oranlar ve AGR-SGR)

\begin{tabular}{|c|c|c|c|c|c|c|c|c|c|}
\hline \multirow{2}{*}{\multicolumn{2}{|c|}{$\begin{array}{l}\text { Bağımsız } \\
\text { Değişken: } \\
\text { AGR-SGR }\end{array}$}} & \multirow{3}{*}{$\begin{array}{c}\begin{array}{c}\text { Korelasyon } \\
\text { Analizi }\end{array} \\
\begin{array}{c}\text { Korelasyon } \\
\text { Katsayis1 }\end{array}\end{array}$} & \multicolumn{7}{|c|}{ Regresyon Analizi İstatistikleri } \\
\hline & & & \multicolumn{2}{|c|}{ Parametre Değerleri } & \multicolumn{3}{|c|}{ Tahminci İstatistikleri } & \multicolumn{2}{|c|}{ Ön Test P Değerleri } \\
\hline $\begin{array}{l}\text { Reg. } \\
\text { No }\end{array}$ & $\begin{array}{l}\text { Bağımlı } \\
\text { Değişken }\end{array}$ & & Katsayı & $\mathrm{t}$ ist. & $\mathrm{N}$ & $\begin{array}{c}\mathrm{p}>\mathrm{F} \\
\text { ist. }\end{array}$ & $\mathrm{R} 2$ & $\begin{array}{l}\mathrm{p}>\text { chi2 } \\
\text { BP/CW }\end{array}$ & $\begin{array}{c}\mathrm{p}>\text { chi } 2 \\
\text { White }\end{array}$ \\
\hline 1 & ROA (1) & $-0.256 * *$ & -0.12 & .20 & 69 & 0.002 & 0.065 & 0.779 & 0.823 \\
\hline 2 & ROA (2) & -0.2 & -0.14 & -3.21 & 69 & 0.002 & 0.068 & 0.528 & 0.855 \\
\hline 3 & ROA (3) & -0.25 & $-0.109^{*}$ & -3.15 & 69 & 0.003 & 0.063 & 0.945 & 0.767 \\
\hline 4 & ROE (1) & $-0.366^{* * *}$ & $-0.310 * * *$ & -3.46 & 69 & 0.001 & 0.134 & 0.376 & 0.811 \\
\hline 5 & ROE (2) & $-0.284 * *$ & $-0.190 * * *$ & -3.13 & 69 & 0.003 & 0.081 & 0.322 & 0.517 \\
\hline 6 & $\mathrm{~F} / \mathrm{K}(1)$ & & & 0.82 & 6 & 0.414 & 0.009 & 0.000 & 0.636 \\
\hline 7 & $\mathrm{~F} / \mathrm{K}(2)$ & 0.122 & 7280 & 1.08 & 69 & 0.283 & 0.015 & 0.000 & 0.601 \\
\hline 8 & & & & 0.11 & 69 & 0.912 & 0.000 & 0.202 & 0.368 \\
\hline 9 & Borç & -0.090 & -0.136 & -0.84 & 69 & 0.401 & 0.008 & 0.648 & 0.578 \\
\hline
\end{tabular}

Not. Tablo 4, iki değişken arasındaki korelasyon katsayılarını ve EKK ile tahmin edilen 9 tek değişkenli yatay kesit regresyon analizi istatistiklerini içermektedir. Bağımsız değişken (AGR-SGR), gerçekleşen büyüme ile sürdürülebilir büyüme oranının farkıdır. Bağımlı değişkenler sırası ile: ortalama, dönem başı ve dönem sonu değerlerine göre belirlenen aktif getirileri ROA(1), ROA(2), ROA(3); dönem baş1 öz kaynak karlılığ1 ROE(1) ve dönem sonu öz kaynak karlılı̆̆1 ROE(2); ortalama Fiyat/Kazanç oranı olan $\mathrm{F} / \mathrm{K}(1), 2015$ y1lı fiyat kazanç oranı $\mathrm{F} / \mathrm{K}(2)$; cari oran (Cari) ve borçlanma oranı (Borç) şeklindedir. ***, ** ve * sırası ile $\% 1, \% 5$ ve $\% 10$ anlamlılık seviyelerini yansıtmaktadır. t-istatistik değerleri dirençli standart hatalardir.

Analiz bulgularına göre 1'den 5'e kadar olan regresyonlarda karlılık değişkenleri ile SGR'den sapma arasındaki ilişki istatistiki olarak anlamlı ve negatiftir. Bu negatif ilişki, AGR-SGR farkı arttıkça aktif karlılığının ve öz kaynak karlılığının azaldığını göstermektedir. AGR-SGR, ortalaması $\% 2$ olan ve -\%27 ile \%58 arasında değişen değerler alan bir değişkendir. Bu değişkenin değerinin sıfirdan düşük olması yetersiz büyüme durumunu ve sıfırdan büyük olması aşırı büyüme durumunu ifade etmektedir. Bir başka ifade ile AGR-SGR artışı aşırı büyüme düzeyinin, düşmesi ise yetersiz büyüme seviyesinin artışı anlamına gelmektedir. AGR-SGR değişkeni ile karlılık değişkenleri arasındaki negatif ilişki, aşırı büyüyen firmaların daha düşük karlılığa sahip olduğu, yetersiz büyüyen firmaların ise yüksek aktif ve öz kaynak karlılığ 1 ile faaliyetini sürdüren firmalar olduğu şeklinde yorumlanabilmektedir. Korelasyon analizi ve regresyon analizi ile ortaya çıkan bu ilişki, değişkenlerin tanımlayıcı istatistikleri ile yapılan ön değerlendirmeleri teyit eder niteliktedir. AGR-SGR farkının F/K oran1, cari oran ve borçlanma oranı ile ilişkisi istatistiki açıdan önemli düzeyde değildir.

Bulgular, SGR'den sapmanın aktif karlılı̆̆ı ile negatif yönde ilişkisi olduğunu gösteren 2 çalışma (Amouzesh vd. 2011; Saputro \& Purwanto, 2013) ile aynı yöndedir. Amouzesh vd. (2011) İran'da AGR-SGR bağımsız değişken iken ROA ile negatif ilişskili (SGR-AGR farkının aktif karlılığı ile pozitif ilişkili) olduğunu, Saputro \& Purwanto (2013) Endonezya'da AGR-SGR bağımlı değişken iken ROA ile ilişkisinin negatif olduğunu göstermiştir. Sürdürülebilir büyüme oranı arttıkça aktif karlılığının arttığını ortaya çıkaran 2 (Rahim \& Saad, 2014; Hartono \& Utami, 2016) çalışma bulguları ile de örtüşmektedir. Rahim ve Saad (2014) 4 Asya ülkesinde, Hartono ve Utami (2016), Endonezya'da SGR'nin, ROA ile pozitif ilişkili olduğunu bulmuştur. Ayrıca 30 Dow Jones firmasında SGR ile hisse başına kar arasında pozitif ilişki raporlayan Babcock (1970) bulguları ile de benzerlik göstermektedir. 
SGR üzerinde en etkili olan bileşeni belirleyebilmek için 69 gözlemden oluşan yatay kesit verilere 2 eşitlik ile EKK regresyon analizi uygulanmış ve dirençli standart hataları içeren analiz istatistikleri Tablo 5'de sunulmuştur.

Tablo 5. Varsayım ve Tahminci Test İstatistikleri (SGR ve SGR Bileşenleri)

\begin{tabular}{|c|c|c|c|c|c|c|c|c|c|}
\hline \multirow{2}{*}{\multicolumn{2}{|c|}{$\begin{array}{c}\text { Bağımsız } \\
\text { Değişken: } \\
\text { SGR }\end{array}$}} & \multicolumn{8}{|c|}{ Regresyon Analizi İstatistikleri } \\
\hline & & \multicolumn{2}{|c|}{ Parametre Değerleri } & \multicolumn{3}{|c|}{ Tahminci İstatistikleri } & \multicolumn{3}{|c|}{ Ön Test P değerleri } \\
\hline $\begin{array}{l}\text { Reg. } \\
\text { No }\end{array}$ & $\begin{array}{l}\text { Bağımsız } \\
\text { Değişken }\end{array}$ & Katsay 1 & $\mathrm{t}$ ist. & $\mathrm{N}$ & $\begin{array}{c}\mathrm{p}>\mathrm{F} \\
\text { ist. }\end{array}$ & $\mathrm{R} 2$ & $\begin{array}{l}\mathrm{p}>\mathrm{chi} 2 \\
\text { BP/CW }\end{array}$ & $\begin{array}{c}\mathrm{p}>\text { chi } 2 \\
\text { White }\end{array}$ & VIF \\
\hline \multirow{4}{*}{10} & $\mathrm{P}$ & $0.949 * * *$ & 5.54 & \multirow{4}{*}{69} & \multirow{4}{*}{0.000} & \multirow{4}{*}{0.613} & \multirow{4}{*}{0.000} & \multirow{4}{*}{0.684} & \multirow{4}{*}{1.28} \\
\hline & $\mathrm{R}$ & $0.193 * * *$ & 7.17 & & & & & & \\
\hline & A & $0.073 * * *$ & 3.62 & & & & & & \\
\hline & $\mathrm{T}$ & $0.028 * * *$ & 3.16 & & & & & & \\
\hline 11 & $\begin{array}{c}\text { ROE (1) } \\
\text { R }\end{array}$ & $\begin{array}{l}0.693 * * * \\
0.203 * * *\end{array}$ & $\begin{array}{c}7.34 \\
10.32\end{array}$ & 69 & 0.000 & 0.820 & 0.000 & 0.000 & 1.03 \\
\hline
\end{tabular}

Not. Tablo 5, 2 SGR bileşen grubunun SGR değişkeni üzerindeki etkisini inceleyen EKK yatay kesit regresyon analizi parametre değerlerini raporlamıştır ***, ** ve $*$ sırası ile $\% 1, \% 5$ ve $\% 10$ anlam seviyelerini yansıtmaktadır. t-istatistik değerleri dirençli standart hatalardır. Sabit varyans hipotezi $\mathrm{BP} / \mathrm{CW}$ testi ile her iki eşitlik için ret edilmiştir. White testi 10. eşitlik için sabit varyansın varlığını kabul ederken 11. eşitlik için ret etmiştir.

SGR üzerinde PRAT bileşenleri etkisini inceleyen 10. eşitlik katsayı değerlerine göre değişkenlerin etkinlik sıralaması kar marjı, alıkoyma oranı, aktif devir hızı ve öz kaynak çarpanı şeklindedir. SGR bileşenlerinin bir başka ifadesi olan ROE (PAT ortak etkisi) ve R değişkenleri ile SGR ilişkisini içeren 11. eşitlik katsayılarına göre ROE, R'ye göre daha etkilidir ancak alıkoyma oranının katsayısı 10. ve 11 . eşitliğin her ikisinde de birbirine yakındır. SGR'nin en etkili ilk iki bileşeninin kar marjı ve alıkoyma oranı olduğunu gösteren bu bulgular, yabancı piyasalarda yapılan diğer bazı çalışmaların (Seens, 2013; Xiyuan ve Jingui, 2015; Lockwood ve Prombutr, 2010; Jagadish, 2011) sonuçları ile benzerlik göstermektedir. Seens (2013), Kanada KOBİ'lerinin Xiyuan ve Jingui (2015), Çinin yüksek girişimler pazarı firmalarının SGR'lerinin temel belirleyicisinin karlılık olduğunu, Lockwood ve Prombutr (2010), ABD hisse getirisi üzerinde en etkili SGR bileşeninin net kar marjı olduğunu ortaya koymaktadır. Ayrıca Seens (2013) çalışmasında alıkoyma oranı ikinci sırada gelirken Jagadish (2011) çalışmasında Hindistan'ın 2 teknoloji firmasının SGR'sinde alıkonulan karların etkili olduğu raporlanmıştır.

\section{Sonuç}

Büyümenin yönetimi firmanın satış hedeflerinin, işletme verimliliği ve finansal kaynaklarla dikkatli bir şekilde dengelenmesini gerektirmektedir (Horne \& Wachowicz, 2008: 190). Faaliyet ve finansman politikaları ile uyum içinde olan dengeli satış büyümesi oranı olarak Higgins (1977) tarafından geliştirilen finansal sürdürülebilir büyüme oranından, finansal planlama ve büyümeyi yönetme aracı olarak faydalanılmaktadır. İncelenen çalışmalarda, sektör ve firmaların mevcut politikalarını değiştirmeden erişebilecekleri büyüme potansiyeli SGR ile ve bu büyüme potansiyeline yaklaşma durumu AGR-SGR farkı ile değerlendirilmiştir. SGR düzeyinin ve AGR-SGR farkının finansal oranlarla ilişkisi de çalışmalara konu olmuştur. Buna karşılık Türkiye'de sürdürülebilir büyümeye dayalı değerlendirme içeren yeterli çalışmanın 
yapılmadığı gözlenmiştir. Bu çalışma ile yeni hisse senedi ihracının bulunmadı̆̆ durumda firma politikaları ile uyumlu satış büyüme oranı olan Higgins (1977) SGR'si hesaplanarak bu orandan sapmaların yönü belirlenmiştir. 2013-2015 yıllarında 69 BIST imalat şirketinin SGR bileşenleri ve bazı finansal oranlardan oluşan değişkenleri belirlenmiştir. Öncelikle tüm veri seti, aşırı büyüyen, yetersiz büyüyen firmalar ve alt sektörler için ayrı tanımlayıcı istatistikler aracılığ değerlendirmeler yapılmış ve bu değerlendirmeler tüm veri setine uygulanan regresyon ve korelasyon analizleri ile teyit edilmiştir. Ayrıca çalışma, en etkili SGR bileşenini belirleyen regresyon analizini de içermektedir.

2013-2015 yıllarının 3 yıllık ortalama verilerine göre Türkiye'de 69 sanayii şirketinin mevcut finansal kaynakları ve kazanç potansiyelleri ile uyumlu olan sürdürülebilir büyüme oranı \%10'dur. Şirketler \%12 gerçek satış büyümesi ile \%2 aşırı büyüme göstermiştir. Analiz edilen 69 şirketin 46'sı aşırı büyürken 23'ü yetersiz büyümüştür ve iki grubun değişkenlerinin ortalamaları farklılık göstermektedir. Yetersiz büyüyen firmaların sürdürebileceği büyüme oranı \%18 iken gerçekleşen büyümeleri $8 \%$ ve yetersiz büyüme ortalamas1 -\%10 dur. Yetersiz büyüyen firmalar faaliyet ve finansal performansı ve dolayısıyla SGR'si aşırı büyüyen firmalara göre daha yüksek olan firmalardır. Yüksek karlılıklarını, alıkoyma oranları ve borç kullanımı ile yüksek öz kaynak karlılığına dönüştüren bu firmalar büyüme potansiyellerine ulaşmamıştır. Aşırı büyüyen firmalarda sürdürülebilir büyümenin $\% 6$, gerçek büyümenin $\% 14$ olduğu ve aşırı büyüme seviyesinin $8 \%$ olduğu görülmektedir. Aşırı büyüyen firma sınıfında yer alan ve finansal kaynağa ihtiyaç duymadan büyüme potansiyelleri nispeten düşük olan firmalar, düşük karlılık oranlarına rağmen daha yüksek satış büyümesi yaşayan firmalardır. Ayrıca alt sektörlerinin sürdürülebilir büyüme oranı $\% 4.5$ (metal ana sanayi) ile \%15.3 (gıda, içki ve tütün) ${ }^{10}$ arasında olup \%5.4 ile aşırı büyümenin en yüksek olduğu alt sektör taş ve toprağa dayalı sektördür.

Değişkenlerin tanımlayıcı istatistikleri ile yapılan değerlendirmeler regresyon ve korelasyon analizleri ile teyit edilmiştir. Veri setinin finansal sürdürülebilir büyüme oranı ve gerçekleşen büyüme oranı arasındaki farkın aktif karlılığı, öz kaynak karlılığ fiyat kazanç oranı, cari oran ve borçlanma oranına etkisi 11 eşitliğe korelasyon analizi ve tek değişkenli yatay kesit regresyon analizi uygulanarak araştırılmıştır. Oluşturulan 11 eşitliğin 9'u sürdürülebilir büyümeden sapmanın finansal oranlarla ilişkisini, 2'si sürdürülebilir büyümenin ana belirleyicilerini tespit etmeye yöneliktir. Analiz sonuçları, aşırı büyüyen firmaların aktif ve öz kaynak getiri oranlarının düşük olduğunu buna karşılık yetersiz büyümenin yüksek karlılıklarla ilişkilendirildiğini göstermektedir. Sürdürülebilir büyüme oranının bileşenleri arasında en etkili faktörünün kar marjı olduğu söylenebilmektedir.

Mevcut faaliyet ve finansal yapıları ile destekleyemedikleri oranda aşırı büyüyen firmalarının karlılıklarını ve/veya karı alıkoyma oranını artırarak ve/veya daha fazla borç kullanarak SGR'lerini artırmaları mümkün görünmektedir. TCMB verilerine göre imalat sanayinin analiz dönemi için ortalama borçlanma oranı \%62.7' dir ${ }^{11}$

\footnotetext{
${ }^{10}$ En yüksek SGR \%20ile diğer imalat sanayine aittir ancak bu alt sektör tek bir firmadan oluştuğu için bir sonraki en yüksek SGR'ne sahip alt sektör dikkate alınmıştır.

11 TCMB değerleme raporuna dahil edilen 3,469 imalat sanayi firmasının 2013-2015 yılları ortalama borçlanma oranı \%62.7, öz kaynak karlılığ1 \%10.4, aktif karlılı̆̆ \%3.9, cari oranı 1.46, aktif devir hızı 1 'dir (www.tcmb.gov.tr).
} 
(www.tcmb.gov.tr). İmalat sanayii firmaları sabit bir borç-öz kaynak oranını genellikle korumaya eğilimli olsalar da (Gordon, 1962: 38) borçlanma oranı \%43 olan ve sürdürülebilir olmayan büyümesini finanse etmek durumunda olan, bu çalışmada incelenen aşırı büyüyen firmaların finansal kaldıraçtan faydalanma potansiyelleri bulunduğu söylenebilir. Yetersiz büyüyen firmalar ise faaliyet performansı ve finansal yapılarının desteklediği oranın altında büyümektedir. Bu firmalarının fazla fonlarını, hızlı büyüme sağlayacak yatırımlarda veya kar dağıtımı ve borç ödemesi şeklinde kullanma imkânları bulunmaktadır.

$\mathrm{Bu}$ çalışmada kullanılan temel Higgins SGR modelini, yeni öz kaynak ihracına izin vererek, hedef borç oranına kadar borç artışını modele ekleyerek veya nakit akımını dikkate alarak geliştiren modeller kullanılarak da Türk firma ve sektörlerinin SGR'leri hesaplanabilir. Sektörlere özgü büyüme sorunları ve uzun vadeli çözümlerin incelenmesi, büyüme oranlarının hisse senedi getirileri ve finansal başarısızlıklar üzerindeki etkisinin analiz edilmesi, aşırı ve yetersiz büyüme durumlarına etki eden nitel ve nicel diğer faktörlerin belirlenmesi de Türkiye'de daha fazla araştırmayı gerektirebilecek konular arasındadır. 


\section{Kaynakça}

Amouzesh, N., Moeinfar, Z. \& Mousavi, Z. (2011). Sustainable growth rate and firm performance: Evidence from Iran Stock Exchange. International Journal of Business and Social Science. 2(23). 249-255.

Ashta, A. (2008), Sustainable growth rates: Refining a measure. Straegic Change. 17: 207-214: DOI: $10.1002 /$ jsc. 827

Babcock, G.C. (1970). The concept of sustainable growth. Financial Analysts Journal, 26 (3), 108-114.

Burger, J. H., \& Hamman, W. D. (1999). The relationship between the accounting sustainable growth rate and the cash flow sustainable growth rate. South African Journal of Business Management, 30(4), 101-109.

Chang, Y. (2012). Strategy formulation implications from using a sustainable growth model. Journal of Air Transport Management, 20, 1-3.

Chen, H., Gupta, M. C., Lee, A. C., \& Lee, C. (2013). Sustainable growth rate, optimal growth rate, and optimal payout ratio: A joint optimization approach. Journal of Banking \& Finance, 37, 1205-1222. doi:10.1016/j.jbankfin.2012.11.019

Churchill, N.C. \& Mullins, J.W. (2001). How fast can your company afford to grow?, Harvard Business Review, 79 (5), 135-143.

Clouse, M \& McFaddin, S. (1994, abstract), Sustainable growth in the US gas utility industry, Resources Policy, 20 (2), 117-123.

Costa, J. (1997). Challenging growth: How to keep your company's rapid expansion on track. Outlook, 65 (2), 34-39.

Firer, C. (1995). Sustainable growth models. Investment Analysts Journal, 24 (41). 5758.

Fonseka, M. M., Ramos, C. G., Tian, G. (2012). The most appropriate sustainable growth rate model for managers and researchers. The Journal of Applied Business Research, 28 (3), 481-500.

Gordon, M. (1962). The savings investment and valuation of a corporation, The Review of Economics and Statistics, 44 (1), 37-51. doi:10.2307/1926621

Hamman W.D. (1996). Sustainable growth: A cash flow model. Investment Analysts Journal, 25 (43), 57-61.

Hartono, G. C., \& Utami, S. R. (2016) The comparison of sustainable growth rate, firm's performance and value among the firms in Sri Kehati index and IDX30 index in Indonesia stock exchange. International Journal of Advanced Research in Management and Social Sciences.5(5), 68-81.

Higgins, R.C. (1977). How much growth can a firm afford?, Financial Management. 6 (3), 7-16.

Higgins, R.C. (2001). Analysis for Financial Management (6th ed.), New York: McGraw Hill.

Higgins RC. (2012). Analysis for Financial Management (10 th international ed.) Singapore: McGraw-Hill.

Horne, J.C. \& Wachowicz, J.M. (2008). Financial Management (13th ed.), Pearson Education Limited.

Huang, R. \& Liu, G. (2009). Study on the enterprise sustainable growth and the leverage mechanism. International Journal of Business and Management. 4 (3), 2300-205. 
Jagadish R. (2011). Performance analysis with sustainable growth rate: A case study. International Journal of Research in Commerce, Economics and Management. 1 (1), 118-123.

Lockwood, L. \& Prombutr, W. (2010). Sustainable growth and stock returns. The Journal of Financial Research. 33(4), 519-538.

Momčilović, M., Begović, S. V., Tomašević, S., \& Ercegovac, D. (2015). Sustainable growth rate: Evidence from agricultural and food enterprises. Management, 76. 63-75.

Mubeen, M. (2017). Sustainable growth of non-financial firms: Evidence from emerging economies, İhsan doğramac1 Bilkent Üniversity, Master's Thesis. Ankara, Mart 2017.

Olson G.T.\& Pagano, M.S. (2005). A new application of sustainable growth: A multidimensional framework for evaluating the long run performance of bank mergers, Journal of Business Finance \& Accounting, 32(9),1995-2036.

Packard, D. (1957). "Growth from Performance" speech. Agilent Technologies. Box 2, Folder 29, GeneralSpeeches. http://hpmemoryproject.org/an/pdf/growth_from_perf.pdf,erişimtarihi: 09.09.2017

Pandit, N. \& Tejani, R. (2011). Sustainable growth rate of textile and apparel segment of the Indian retail sector. Global Journal of Management and Business Research. $11(6), 38-44$.

Phillips, M., Anderson, S. \& Volker, J. (2004). Understanding small private retail firm growth using the sustainable growth model, Journal of Finance and Accountancy, $1(1), 1-11$.

Platt, H.D., Platt, M.B. \& Chen G.(1995). Sustainable growth rate of firms in financial distress. Journal of Economics and Finance, 19 (2), 147-151.

Rădăşanu, A. C. (2015). Cash-flow sustainable growth rate models. Journal of Public Administration, Finance \& Law, 7, 62-70.

Rahim, N. \& Saad, N. (2014). Sustainable growth of public listed companies (PLC) using capital structure choices and firm performance in an Asean Market. Proceeding of the Global Summit on Education GSE 2014, 4-5 March 2014, Kuala Lumpur, Malaysia. 433-444.

Ross, S.A., Westerfield, R. W. \& Jordan. B. D. (2003). Fundamentals of corporate finance (6th ed.), Boston: McGraw-Hill/Irwin

Saputro, A. W. \& Purwanto, A. (2013). Pengaruh Hubungan Kinerja, Likuiditas dan Return Saham Terhadap Deviasi Actual Growth Rate Dari Sustainable Growth Rate Pada Perusahaan Manufaktur di Bursa Efek Indonesia, Diponegoro Journal Of Accounting, 2 (3), 1-12.

Seens, D. L. (2013). Small and medium-size enterprises growth study: Actual vs.sustainable growth. Industry Canada. Small Business Branch Reseach and Analysis Directorate. 1-29.

Sempath, R. \& Kambil, A. (2005). Sustainable Growth: Is There Room to Grow? Deloitte. 1-6.

Wet, J. (2013). Earnings per share as a measure of financial performance: Does it obscure more than it reveals?, Corporate Ownership \& Control, 10 (4), 265-275.

Xiyuan, H. \& Jingui, Z. (2015). Research on the Financial Sustainable Growth of the Listed Companies on GEM. International Business and Management. 10 (2), 3237. 
Yakimova, V. (2013, abstract) Perspective analysis of financial position of capital intensive enterprises based on the sustainable growth model. Journal of Corporate Finance Research. 1 (25).

Web Kaynaklar1

https://www.kap.org.tr, erişim tarihi 03.08.2017-24.12.2017

http://www.borsaistanbul.com/veriler/verileralt/hisse-senetleri-piyasasi-verileri, erişim tarihi 13.08.2017

http://www.borsaistanbul.com/veriler/verileralt/gunluk-bulten-arsiv, erişim tarihi 13.08.2017

http://www3.tcmb.gov.tr/sektor/2016/menu.php, erişim tarihi 09.12.2017

http://www3.tcmb.gov.tr/sektor/2015/menu.php, erişim tarihi 09.12.2017

Türkiye Cumhuriyeti Merkez Bankası (2016), Sektör Bilançoları (2013-2015) Değerlendirme Raporu, İstatistik Genel Müdürlügü, Reel Sektör Verileri Müdürlüğü, http://www.tcmb.gov.tr, erişim tarihi 09.12.2017

Türkiye Cumhuriyeti Merkez Bankası (2015), Sektör Bilançoları (2012-2014) Değerlendirme Raporu, İstatistik Genel Müdürlügü̈, Reel Sektör Verileri Müdürlüğü, http://www.tcmb.gov.tr, erişim tarihi 09.12.2017 


\section{Financial Sustainable Growth Rate and Financial Ratios: A Research on Borsa İstanbul Manufacturing Firms}

\author{
Arzu Şahin \\ Adana Science and Technology University \\ Faculty of Business \\ Department of International Trade and \\ Finance, Adana, Turkey \\ orcid.org/0000-0002-9944-1791 \\ asahin@adanabtu.edu.tr
}

\author{
Bahadır Ergün \\ Adana Bilim ve Teknoloji Üniversitesi \\ Faculty of Business \\ Department of International Trade and \\ Finance, Adana, Turkey \\ orcid.org/0000-0002-0844-412X \\ bergun@adanabtu.edu.tr
}

\section{Extensive Summary}

\section{Introduction}

While sales growth is one of the performance indicators for a business (Momčilović, Begović, Tomašević \& Ercegovac 2015: 63), it does not have to be maximized at all cases. Despite positive reaction from managers, shareholders and market, rapid growth brings with it the risk of bankruptcy if the need for financial resources cannot be managed well. Slow-growing companies face with problems such as growth pressures from shareholders as well as management of excess funds. The "financial sustainable growth rate" (SGR) proposed by Robert C. Higgins (1977), under certain assumptions, represents the maximum rate of growth that firms can realize in their sales without exhausting their financial resources (Higgins, 2012: 123). Comparing the actual growth rate (AGR) of a firm to the sustainable growth rate reveals important information on the key financial issues that are relevant to management. (Higgins, 2012: 141). The problem of AGR being higher than SGR may be expressed as the problem of over-growth (or rapid growing), and the vice versa may be referred as the problem of under-growth (or slow growing).

The SGR may be used as a device to identify potential growth problems of sectors or firms and to evaluate financial performance in a holistic approach that focuses on growth management. Examining the SGR's sub-components that reveal the firm's financing and operating strategy may also guide the searching for determinants of problems stemming from the inability of growth management. In the literature review, it has been observed that SGR has been used as an instrument for managing and measuring performance at the firm and industry level. These studies are international studies that develop the SGR model, assess the growth according to SGR level and analyse the impact of SGR and deviations from SGR (as the difference between AGR and SGR) on firm performance.

It was observed that there had been inadequate research, except Mubeen (2017), which calculated SGR for the Turkish sector and firms. With this study, it was aimed to determine Higgins (1977) SGR, to identify over-growth and under-growth companies, to analyse the effect of deviations from SGR (by taking the difference AGR and SGR) on some financial ratios for the data sets selected among the publicly traded companies in Turkey. 


\section{Meterial and Method}

In this study, the widely used SGR model developed by Higgins (1977) as the optimal sales growth rate consistent with operating and financing policies was employed. Higgins (1977) SGR were calculated over the 3-year average of 2013-2015 period of 69 publicly traded manufacturing companies listed on the Borsa İstanbul (BIST). The Higgins (1977) SGR model was based on an analysis of the manufacturing industry. As of 2015, compared to the sales volume of 18 sectors, the share of manufacturing industry in Turkey was about 50\% (TCMB, 2016: 6, www.tcmb.gov.tr). Therefore, the dataset consisted of 69 manufacturing firms that met some criteria (group A, net income, data for all period ...etc.), among the 181 BIST manufacturing firms. Variables based on the financial data of 69 companies were obtained from financial statements and footnotes published on the Public Disclosure Platform (Kamu Aydınlatma Platformu, www.kap.org.tr).

Correlation analysis and univariate cross-section regression analysis methods were utilized to investigate the effect of AGR-SGR difference on the return on assets (ROA), return on equity (ROE), price/earnings ratio $(\mathrm{P} / \mathrm{E})$, debt ratio (Debt), current ratio (Current) and to determine the most effective component of SGR. The relationships between the independent variable of AGR-SGR and dependent variables covering ROA, ROE, P/E, Debt, and Current ratios were investigated in 9 of the the 11 equations established. Remaining 2 regression equations regress the SGR on subcomponents of SGR to determine the main component.

The SGR ( $\mathrm{SGR}=\mathrm{R} \times \mathrm{ROE}_{\mathrm{bop}}$ ) was calculated by multiplying return on equity $\left(\mathrm{ROE}_{\mathrm{bop}}\right)$ with retention rate $(\mathrm{R})$ as in some other studies (Pandit \& Tejani, 2011; Hartono \& Utami, 2016; Amouzesh vd. 2011, Momčilović vd. 2015; Jagadish, 2011). Being in the compliance with the assumption that there is no new equity issuance, the equity value at the beginning of the period (bop) was used. AGR was the sales growth rate among two year. ROA was entered to the analysis as three alternatives taking into account the average of beginning and ending assets (ROA1), the beginning assets (ROA2) and ending assets (ROA3). Two ROE ratios were measured both with the equity amounts at beginning of the period (ROE1) and the ending of the period (ROE2). One of the Price/Earnings $(\mathrm{P} / \mathrm{E})$ ratios covered the three year average $(\mathrm{P} / \mathrm{E} 1)$ while other $\mathrm{P} / \mathrm{E}$ ratio reflected the last year-end value (P/E2). Other two dependent variables, current ratio and debt ratio, were calculated on current year accounts. Besides, PRAT variables were identified to examine the components of SGR (SGR=PRAT). P denoted profit margin (net profit/revenue) while $\mathrm{R}$ refered to retention ratio (1-divident rate). A was used to express the asset turnover rate (revenue/total asset). $\mathrm{T}$ is the financial leverage (total asset/beginning equity).

\section{Conclusion and Discussion}

According to the 3 year averages, SGR that is compatible with existing financial resources and earning potential for the 69 manufacturing companies in Turkey is $10 \%$. Companies were experienced $2 \%$ over-growth with $12 \%$ AGR. Under-growth companies have been growing slowly at a rate of $8 \%$ AGR than their potential SGR of $18 \%$. Under-growth companies had higher operating and financial performance and therefore higher SGR than over-growing firms. These firms, which turned their high profitability into high equity returns with retention rates and financial leverage, did not reach their growth potential. While actual sales growth rate for firms that were in over- 
growth category was $14 \%$, their SGR was $6 \%$. The over-growth companies that had lower growth potential without additional financial resources achieved high sales increases in spite of their lower profitability. Graph 1 show that the SGR, PRAT components (except A), ROA's, ROE's and current ratio all were higher for undergrowing group than that of the overly growing group. In addition, the sub-sector's SGR was between $4.5 \%$ (basic metal industries) and 15. 3\% (food, beverage and tobacco) and over-growth rate got the highest value in non-metallic mineral products sub-sector.

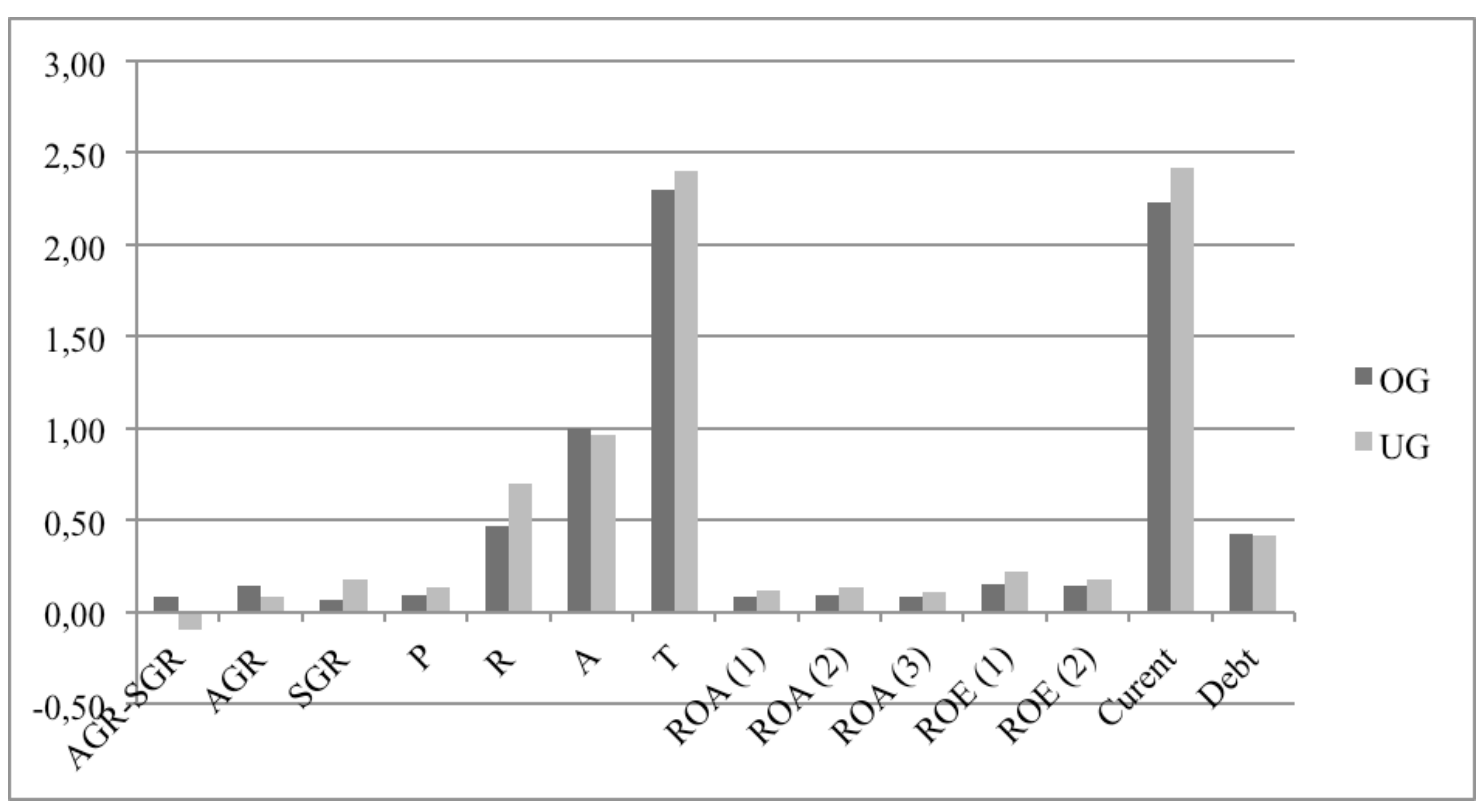

Graph 1. Means of Variables for Over-Growth and Under-Growth Firms

Note: The P/E ratio is not included in the Graph 1 generated by the means data of Over-Growth (OG) and Under-Growth (UG) companies.

Interpretations made with descriptive statistics of variables were confirmed by regression and correlation analyses. According to the findings of the analysis, the relationships between profitability variables, ROA and ROE, and AGR-SGR were negative and statistically significant. This negative relationship indicated that as the AGR-SGR increased, the ROA and ROE decreased. AGR-SGR was a variable with a mean of $2 \%$ and values ranging from $-27 \%$ to $58 \%$. The value of this variable less than zero means under-growth and greater than zero means over-growth. In other words, increase of AGR-SGR is an indicator of over- growth level, decrease of AGR-SGR indicates deepness of under-growth level. The negative relationship between AGR-SGR variables and profitability variables can be interpreted as the fact that over-growing firms have lower profitability, while under-growing firms operate with high asset and equity profitability. The relations of AGR-SGR with other financial ratios $(\mathrm{P} / \mathrm{E}$, Current and Debt) were not statistically significant. This findings is consistent with some of the previous studies (Amouzesh et al. 2011; Saputro \& Purwanto, 2013) offering evidence about a negative relationship between AGR-SGR and ROA. There are also similarities with the findings of two studies (Rahim \& Saad, 2014; Hartono \& Utami, 2016) confirming that SGR is positively related to ROA. Examining the related regressions coefficients, The PRAT variables could be listed in order of importance as profit margin, the retention rate, the asset turnover rate and the equity multiplier. Findings suggesting that the most important two components were profit margins and retention 
rate are similar to the results of some other studies (Seens, 2013; Xiyuan and Jingui, 2015; Lockwood and Prombutr, 2010; Jagadish, 2011) conducted in foreign markets.

For the over-growing firms whose rapid growth are not supported by their existing operating and financial structures, raising profitability, retention rate or debt usage to be able to improve SGR might be recommended. According to the TCMB data, the average borrowing rate of the manufacturing industry for the analysis period was $62.7 \%$ (www.tcmb.gov.tr) and it could be said that the over-growing firms examined in this study had the potential to benefit from the financial leverage. Under-growing firms that are growing slowly than the rate supported by their operational performance and financial structures had the possibility to use the excess funds in high growth potential investments or in dividend payment or debt repayment.

The SGRs of the Turkish firms and sectors can also be studied employing expanded forms of basic Higgings SGR model by allowing for new equity issuance or by modelling debt growth up to the target debt ratio or by focusing on cash flow. Industry specific growth problems, long-term solutions, the impact of growth rates on stock returns and financial failures and quantitative and qualitative determinants of being overgrowth or undergrowth are among the issues that may require further investigation in Turkey. 